\title{
FORWARD GUIDANCE
}

\author{
Marcus Hagedorn \\ Jinfeng Luo \\ Iourii Manovskii \\ Kurt Mitman
}

Working Paper 24521

http://www.nber.org/papers/w24521

\author{
NATIONAL BUREAU OF ECONOMIC RESEARCH \\ 1050 Massachusetts Avenue \\ Cambridge, MA 02138 \\ April 2018
}

This paper has been prepared for the Carnegie-Rochester Conference Series on Public Policy honoring the contributions of Charles Plosser to Economics.We thank Jeff Lacker for many detailed comments. We gratefully acknowledge financial support from the National Science Foundation Grant No. SES-1357903, FRIPRO Grant No. 250617, the European Research Council ERC Starting Grant 759482, and the Ragnar S oderbergs stiftelse. The views expressed herein are those of the authors and do not necessarily reflect the views of the National Bureau of Economic Research.

NBER working papers are circulated for discussion and comment purposes. They have not been peer-reviewed or been subject to the review by the NBER Board of Directors that accompanies official NBER publications.

(C) 2018 by Marcus Hagedorn, Jinfeng Luo, Iourii Manovskii, and Kurt Mitman. All rights reserved. Short sections of text, not to exceed two paragraphs, may be quoted without explicit permission provided that full credit, including $\left({ }^{\circ}\right.$ notice, is given to the source. 
Forward Guidance

Marcus Hagedorn, Jinfeng Luo, Iourii Manovskii, and Kurt Mitman

NBER Working Paper No. 24521

April 2018

JEL No. E21,E30,E52,E58,E62

\begin{abstract}
We assess the power of forward guidance_-promises about future interest rates — as a monetary tool in a liquidity trap using a quantitative incomplete-markets model. Our results suggest the effects of forward guidance are negligible. A commitment to keep future nominal interest rates low for a few quarters - although macro indicators suggest otherwise-has only trivial effects on current output and employment. We explain theoretically why in complete markets models forward guidance is powerful—generating a "forward guidance puzzle"—and why this puzzle disappears in our model. We also clarify theoretically ambiguous conclusions from previous research about the effectiveness of forward guidance in incomplete and complete markets models.
\end{abstract}

\author{
Marcus Hagedorn \\ Department of Economics \\ University of Oslo \\ Box 1095 Blindern \\ 0317 Oslo, Norway \\ marcus.hagedorn@econ.uio.no \\ Jinfeng Luo \\ Department of Economics \\ University of Pennsylvania \\ 160 McNeil Building \\ 3718 Locust Walk \\ Philadelphia, PA 19104 \\ jinfengl@sas.upenn.edu
}

\author{
Iourii Manovskii \\ Department of Economics \\ University of Pennsylvania \\ 160 McNeil Building \\ 3718 Locust Walk \\ Philadelphia, PA 19104 \\ and NBER \\ manovski@econ.upenn.edu \\ Kurt Mitman \\ Institute for International Economic Studies \\ Stockholm University \\ 10691 Stockholm \\ SWEDEN \\ kurt.mitman@iies.su.se
}




\section{Introduction}

As a response to the decline in economic activity during the Great Recession, the monetary authority lowered the nominal interest rate to zero in an attempt to stimulate output and employment. Having reached the limit of conventional monetary policy (the zero lower bound) and in the face of high unemployment and low output, the monetary authority attempted to provide further accommodation by announcing its forecast of future policy rates. In the liquidity trap, this "forward guidance" has become one of the main new tools for the monetary authority to conduct policy.

Understanding the efficacy of this new policy tool and the mechanism through which it operates is crucial for helping to fight future recessions. In the benchmark model for monetary policy analysis, the representative-agent New Keynesian (RANK) model, forward guidance is very effective, driven by the effect on intertemporal substitution (Carlstrom et al., 2015). The commitment to keep future interest rates at zero despite recovering economic conditions (such as rising inflation) yields large positive contemporaneous output effects. More generally, cutting future nominal interest rates has much larger effects than contemporaneous cuts and, paradoxically, the effect is increasing in the horizon of the announced cut. This feature of the RANK model gave rise to what is referred to as the "Forward Guidance Puzzle" (Del Negro et al., 2012).

Since the strong effects of forward guidance are driven by intertemporal substitution, one hypothesis for the resolution of the puzzle was to depart from the assumption of complete markets and instead incorporate incomplete asset markets. Most prominently, McKay et al. (2016) make the case for forward guidance being less effective in incomplete than in complete markets. In contrast, Werning (2015) argues that forward guidance is equally effective in complete and incomplete markets models. Thus, the question of how to resolve the puzzle remained open, and the extent to which incomplete markets help to resolve it was unclear. McKay et al. (2016) say they help quite a bit, though even in their framework a few quarters of forward guidance is powerful enough to effectively prevent "Great Recessions." Werning (2015) says incomplete markets help very little or not at all. But both agree that forward guidance is likely to be an potent monetary tool.

This paper resolves the puzzle — providing valuable insights to future policy makers — 
and simultaneously reconciles the disagreements outstanding in the literature. Our starting point is the same incomplete markets model as used by Werning (2015) and McKay et al. (2016). We add several features to the model which bring it closer to the data and provide a quantitative assessment disciplined by data that builds on a large literature of incompletemarkets models. To calibrate the incomplete market/ household block of the model we follow Krueger et al. (2016), which allows the model to replicate income dynamics, and the income and wealth distribution as observed in the data. This allows us to better match the observed individual and the aggregate demand response which is essential to reliably infer demand movements in response to policy changes. We also incorporate that government bonds are nominal a characteristic feature of for example the U.S. bonds market. For the output block, we follow the large New Keynesian literature (Christiano et al., 2005) and incorporate rigid adjustments of wages in addition to rigidity in prices.

The key finding is that the effects of forward guidance are small and the "forward guidance puzzle" disappears. A commitment to keep nominal interest rates low for a few quarters despite the fact that macro indicators signal that interest rates should be raised has minimal effects on current output and employment. Future changes in nominal interest rates are less effective than current ones and the contemporaneous output effects of future interest rate promises are falling in the horizon of the promise. It is important to note that contemporaneous changes to nominal interest rates are quite powerful in our model, so that our findings are not due to a more general ineffectiveness of monetary policy in the model.

To help understand our key result, we first show how the results in Werning (2015) and McKay et al. (2016) depend on their assumptions on income dynamics, on the redistribution of profits and on the allocation of taxes. Specifically we show that through varying those distributional assumptions, forward guidance can be more, equally or less effective in incomplete markets models than in complete markets models. ${ }^{1}$

Given this seemingly ambiguous prediction, what then explains our findings? We differ from the model considered in Werning (2015) and McKay et al. (2016) along two crucial dimensions. Our first modeling deviation is that we allow for the empirically relevant level of

\footnotetext{
${ }^{1}$ Werning (2015) made a related theoretical point. We show that these theoretical arguments are quantitatively relevant within the framework of McKay et al. (2016) and relate the quantitative results to the fiscal policy induced redistribution emphasized in our theoretical analysis.
} 
wage rigidities. Profits are inversely proportional to wages in the model implying that if wages are not very volatile, neither are profits. Moreover, profits are small in our model, in line with the data. Thus, movements in profits are small and they do not induce large distributional consequences. This is contrast to e.g. McKay et al. (2016) who assumed flexible and thus highly volatile wages and profits.

A second difference is that our quantitative assessment takes into account that government bonds, transfers and taxes are (partially) nominal. This assumption paired with incomplete markets generates small movements in the real interest rate from forward guidance, indicating that the theoretical findings of Hagedorn $(2016,2018)$ carry over to realistically calibrated incomplete-markets models. ${ }^{2}$ This is relevant because forward guidance operates in part through changing inflation expectations (and thus real interest rates), which generates feedback onto current prices and output. In complete-markets models, such movements in real rates are sizeable and translate to higher current consumption (through the intertemporal substitution channel), and thus yield higher employment today. In contrast, we find in our incomplete markets model that the change in real interest rates is small implying that the intertemporal substitution channel is weak as well.

To summarize, in incomplete markets models the effect of forward guidance operates through a distributional channel - induced by movements in prices, wages, and interest ratesand an intertemporal substitution channel. We find that both channels are muted when markets are incomplete in the presence of the empirically relevant nominal rigidities and a partially nominal government budget, implying the overall ineffectiveness of forward guidance. The theoretical arguments for our findings are quite general, so that we conclude that forward guidance is not a powerful monetary policy tool, even in a liquidity trap.

The paper is organized as follows. Section 2 presents the basic incomplete markets model with price rigidities similar to the one used by McKay et al. (2016). Using this framework, in Section 3 we study forward guidance in incomplete and complete markets models theoretically and provide quantitative examples to illustrate our theoretical findings. In Section 4 we extend

\footnotetext{
${ }^{2}$ The logic underlying this finding is that higher prices induced by forward guidance lower the real value of government bonds, which are considered net wealth by households, inducing a negative demand response in our incomplete markets model. This negative consumption response puts downward pressure on marginal costs, and thus prices, counteracting the attempts of forward guidance to increase prices. As a consequence, the equilibrium response of the real interest rate required to equate demand and supply is small.
} 
the model to include rigid adjustment of wages and nominal government bonds. We calibrate this model and conduct a quantitative evaluation of the effects of forward guidance. Section 5 concludes.

\section{Model}

To facilitate comparison with the existing results in the literature, we develop the model in stages. In this Section we describe a basic heterogeneous-agent incomplete-markets model (Aiyagari, 1994, 1995) with price rigidities that closely follows the framework of McKay et al. (2016) with minor modifications. Specifically, we introduce a more general class of tax functions and replace pricing frictions a la Calvo (1983) with those in the style of Rotemberg (1982). These modifications facilitate the theoretical analysis and quantitative discussion to follow. In

Section 4, we will extend this basic model to incorporate the two empirically relevant features — wage rigidity and a nominal government budget - for the full quantitative analysis.

As is standard in the New Keynesian literature, final good producers in the model combine intermediate goods to produce a good sold in a competitive market. Intermediate goods producers are monopolistically competitive. They set a price they charge to the final good producer to maximize profits taking into account the price adjustment costs they face. The intermediate goods are produced with labor, rented in competitive markets.

\subsection{Households}

The economy consists of a continuum of agents normalized to measure 1 with CRRA preferences over consumption and additively separable preferences for leisure:

$$
U=E_{0} \sum_{t=0}^{\infty} \beta^{t} u\left(c_{t}, h_{t}\right)
$$

where

$$
u(c, h)= \begin{cases}\frac{c^{1-\sigma}-1}{1-\sigma}-g(h) & \text { if } \sigma \neq 1 \\ \log (c)-g(h) & \text { if } \sigma=1,\end{cases}
$$

$\beta \in(0,1)$ is the discount factor and $g(h)$ is the disutility of labor. Agents' labor productivity $\left\{s_{t}\right\}_{t=0}^{\infty}$ is stochastic and is characterized by an $N$-state Markov chain that can take on values 
$s_{t} \in \mathcal{S}=\left\{s_{1}, \cdots, s_{N}\right\}$ with transition probability characterized by $p\left(s_{t+1} \mid s_{t}\right)$ and $\int s_{t}=1$. Agents rent their labor services, $h_{t} s_{t}$, to firms for a real wage $w_{t}$ and their real assets $a_{t}$ to the bond market for a real rent $r_{t}$ which satisfies $\left(1+r_{t}\right)=\frac{1+i_{t}}{1+\pi_{t}}$, where $1+\pi_{t}=\frac{P_{t}}{P_{t-1}}$ is the inflation rate $\left(P_{t}\right.$ is the price of the final good $)$ and $\left(1+i_{t}\right)$ is the nominal interest rate.

Thus, at time $t$ an agent faces the following budget constraint:

$$
c_{t}+a_{t+1}=\left(1+r_{t}\right) a_{t}+w_{t} h_{t} s_{t}-T_{t}\left(w_{t} h_{t} s_{t}, s_{t}\right)+d_{t}
$$

where $d_{t}$ are dividends from firms and $T_{t}\left(w_{t} h_{t} s_{t}, s_{t}\right)$ is the tax function which can take positive or negative (transfers) values and can depend on agent's labor earnings and productivity. Agents take prices and wages as given. We can rewrite the agent's problem recursively as follows:

$$
\begin{gathered}
V(a, s ; \Omega)=\max _{c \geq 0, a^{\prime} \geq 0} u(c, h)+\beta \sum_{s \in \mathcal{S}} p\left(s^{\prime} \mid s\right) V\left(a^{\prime}, s^{\prime} ; \Omega^{\prime}\right) \\
\text { subj. to } \quad c+a^{\prime}=(1+r) a+w h s-T(w h s, s)+d \\
\Omega^{\prime}=\Upsilon(\Omega),
\end{gathered}
$$

where $\Omega(a, s) \in \mathcal{M}$ is the distribution on the space $X=A \times S$, agents asset holdings $a \in A$ and labor productivity $s \in S$, across the population, which will together with the policy variables determine the equilibrium prices. $\Upsilon$ is an equilibrium object that specifies the evolution of the distribution $\Omega$ and $\mathcal{M}$ is the set of probability measures on $X$.

\subsection{Production}

Final Good Producer A competitive representative final goods producer aggregates a continuum of intermediate goods indexed by $j \in[0,1]$ and with prices $p_{j}$ :

$$
Y_{t}=\left(\int_{0}^{1} y_{j t}^{\frac{\epsilon-1}{\epsilon}} d j\right)^{\frac{\epsilon}{\epsilon-1}}
$$

where $\epsilon$ is the elasticity of substitution across goods. Given a level of aggregate demand $Y_{t}$, cost minimization for the final goods producer implies that the demand for the intermediate 
$\operatorname{good} j$ is given by

$$
y_{j t}=y\left(p_{j t} ; P_{t}, Y_{t}\right)=\left(\frac{p_{j t}}{P_{t}}\right)^{-\epsilon} Y_{t}
$$

where $P_{t}$ is the (equilibrium) price of the final good and can be expressed as

$$
P_{t}=\left(\int_{0}^{1} p_{j t}^{1-\epsilon} d j\right)^{\frac{1}{1-\epsilon}}
$$

Intermediate good producer Each intermediate good $j$ is produced by a monopolistically competitive producer using labor input $n_{j}$. The production technology is linear,

$$
y_{j t}=n_{j t} .
$$

Intermediate producers hire labor at the nominal wage $P_{t} w_{t}$ in a competitive labor market. With this technology, the real marginal cost of a unit of intermediate good is

$$
m c_{j t}=w_{t}
$$

Each firm chooses its price to maximize profits subject to price adjustment costs as in Rotemberg (1982). These adjustment costs are measured in units of aggregate output and are given by a quadratic function of the change in prices above and beyond steady state inflation $\bar{\Pi}$,

$$
\Theta\left(p_{j t}, p_{j t-1} ; Y_{t}\right)=\frac{\theta}{2}\left(\frac{p_{j t}}{p_{j t-1}}-\bar{\Pi}\right)^{2} Y_{t}
$$

Given last period's individual price $p_{j t-1}$ and the aggregate state $\left(P_{t}, Y_{t}, w_{t}, r_{t}\right)$, the firm chooses this period's price $p_{j t}$ to maximize the present discounted value of future profits. The firm satisfies all demand by hiring the necessary amount of labor,

$$
n_{j t}=y\left(p_{j t} ; P_{t}, Y_{t}\right)=\left(\frac{p_{j t}}{P_{t}}\right)^{-\epsilon} Y_{t}
$$

The firm's pricing problem is

$$
V_{t}\left(p_{j t-1}\right) \equiv \max _{p_{j t}} \frac{p_{j t}}{P_{t}} y\left(p_{j t} ; P_{t}, Y_{t}\right)-w_{t} y\left(p_{j t} ; P_{t}, Y_{t}\right)-\frac{\theta}{2}\left(\frac{p_{j t}}{p_{j t-1}}-\bar{\Pi}\right)^{2} Y_{t}+\frac{1}{1+r_{t}} V_{t+1}\left(p_{j t}\right)
$$


In equilibrium all firms choose the same price, and thus, aggregate consistency implies $p_{j t}=P_{t}$ for all $j$ and $t$. Thus, $\frac{p_{j t}}{p_{j t-1}}=\frac{P_{t}}{P_{t-1}}=\pi_{t}$ and $\frac{p_{j t+1}}{p_{j t}}=\frac{P_{t+1}}{P_{t}}=\pi_{t+1}$.

Some algebra (in the appendix) yields the New Keynesian Phillips Curve

$$
(1-\epsilon)+\frac{\epsilon}{1-\alpha} w_{t}-\theta\left(\pi_{t}-\bar{\Pi}\right) \pi_{t}+\frac{1}{1+r_{t}} \theta\left(\pi_{t+1}-\bar{\Pi}\right) \pi_{t+1} \frac{Y_{t+1}}{Y_{t}}=0 .
$$

The adjustment cost are "as-if", that is they are not resource costs but price setters behave as if they were, for example because they affect utility. We make this assumption to avoid counterfactual "price-adjustment booms" that would arise from the large resource costs associated with large price movements in the liquidity trap. The equilibrium real profit of each intermediate goods firm is then

$$
d_{t}=Y_{t}-w_{t} Y_{t}
$$

\subsection{Government}

The government issues real bonds $b_{t+1}$ and collects real taxes $T_{t}\left(w_{t} h_{t} s_{t}, s_{t}\right)$ so that the government budget constraint is given by:

$$
b_{t+1}=\left(1+r_{t}\right) b_{t}-\int T_{t}\left(w_{t} h_{t} s_{t}, s_{t}\right) d \Omega_{t}
$$

Note that, in our enriched quantitative model in Section 4, both bonds and taxes will be nominal.

\subsection{Equilibrium}

Market clearing requires that the labor demanded by the firm is equal to the labor supplied by households and that the bonds issued by the government equals the amount of assets provided by households:

$$
\begin{aligned}
b_{t+1} & =\int \sum_{a_{t}} \sum_{s_{t} \in \mathcal{S}} a_{t+1}\left(a_{t}, s_{t}\right) d \Omega_{t} \\
H_{t} & =\int h_{t}\left(a_{t}, s_{t}\right) d \Omega_{t}=\int n_{j t} d j
\end{aligned}
$$


where $a_{t+1}\left(a_{t}, s_{t}\right)$ and $h_{t}\left(a_{t}, s_{t}\right)$ are the asset and hours choice, respectively, of an agent with asset level $a_{t}$ and period labor productivity $s_{t}$.

Definition: A monetary competitive equilibrium is a sequence of prices $P_{t}$, real tax functions $T_{t}: \mathcal{R} \times \mathcal{S} \rightarrow \mathcal{R}$, real bonds $b_{t}$, value functions $v_{t}: X \times \mathcal{M} \rightarrow \mathcal{R}$ with policy functions $a_{t}: X \times \mathcal{M} \rightarrow \mathcal{R}_{+}$and $c_{t}: X \times \mathcal{M} \rightarrow \mathcal{R}_{+}$, hours $H_{t}, n_{j t}: \mathcal{M} \rightarrow \mathcal{R}_{+}$, pricing functions $r_{t}: \mathcal{M} \rightarrow \mathcal{R}$ and $w_{t}: \mathcal{M} \rightarrow \mathcal{R}_{+}$, and a law of motion $\Upsilon: \mathcal{M} \rightarrow \mathcal{M}$, such that:

1. $v_{t}$ satisfies the Bellman equation with corresponding policy functions $a_{t}$ and $c_{t}$ given price sequences $r_{t}(), w_{t}()$ and hours $H_{t}$.

2. Prices are set optimally by firms taking wages as given.

3. For all $\Omega_{t} \in \mathcal{M}$ :

$$
\begin{aligned}
b_{t+1} & =\int a_{t+1}\left(a_{t}, s_{t}\right) d \Omega_{t}, \\
H_{t} & =\int n_{j t} d j=\int h_{t}\left(a_{t}, s_{t}\right) d \Omega_{t}, \\
Y_{t}=H_{t} & =\int c\left(a_{t}, s_{t}\right) d \Omega_{t} .
\end{aligned}
$$

4. Aggregate law of motion $\Upsilon$ generated by $a^{\prime}$ and $p$.

\section{Forward Guidance in Complete and Incomplete mar- kets Models: Theory and Examples}

In this Section we consider whether forward guidance is more powerful in complete or in incomplete markets models. Our main result is that there is no clear answer to this question. It depends on the distributional consequences of forward guidance whether forward guidance is more or less powerful in incomplete than in complete markets models. We first address this issue theoretically and explain the reason for this ambiguous finding and then move to a quantitative analysis using the model in McKay et al. (2016). Within this model we show that small changes to how fiscal policy is conducted lead to opposite findings when comparing complete and incomplete markets. 


\subsection{Theory}

Our starting point for the model comparison is the outcome of policy experiments - forward guidance or not - in a New Keynesian complete markets model, which arises as a special case of the incomplete markets model when all households are identical and $s \equiv 1$. Let the outcome of such an experiment in the complete markets model be sequences of hours, $H_{t}^{C M}$, consumption, $C_{t}^{C M}$, wages, $w_{t}^{C M}$, dividends, $D_{t}^{C M}$ and gross real interest rates, $R_{t}^{C M}=1+r_{t}^{C M}$.

Define the percentage deviations from steady state (e.g., in response to forward guidance) of the impulse responses of consumption, hours, wages and real interest rates:

$$
\begin{aligned}
& \gamma_{t}^{C}=\frac{C_{t}^{C M}}{C_{s s}^{C M}} \quad[\text { Consumption }] \\
& \gamma_{t}^{H}=\frac{H_{t}^{C M}}{H_{s s}^{C M}}, \quad[\text { Hours }] \\
& \gamma_{t}^{Y}=\frac{Y_{t}^{C M}}{Y_{s s}^{C M}}, \quad[\text { Output }] \\
& \gamma_{t}^{D}=\frac{D_{t}^{C M}}{D_{s s}^{C M}}, \quad[\text { Dividends }] \\
& \left.\gamma_{t}^{w}=\frac{w_{t}^{C M}}{w_{s s}^{C M}}, \quad \text { [Wages }\right] \\
& \gamma_{t}^{R}=\frac{R_{t}^{C M}}{R_{s s}^{C M}}, \quad \text { [Gross Real Interest Rate] }
\end{aligned}
$$

where $C_{s s}^{C M}, H_{s s}^{C M}, Y_{s s}^{C M}, D_{s s}^{C M}, R_{s s}^{C M}$ and $w_{s s}^{C M}$ are steady-state aggregate consumption, hours, output, dividends, real interest rates and wages in the underlying complete markets model respectively. Since the price-adjustment costs are as-if, consumption, output and hours always coincide and deviate by the same percentage,

$$
\gamma_{t}:=\gamma_{t}^{C}=\gamma_{t}^{H}=\gamma_{t}^{Y}
$$

In the incomplete markets model in a steady state, i.e. in the absence of any aggregate shocks or policy interventions, the wage is $w_{s s}^{I M}$ and the real interest rate is $R_{s s}^{I M}=1+r_{s s}^{I M}$. Each household $i$ consumes $c_{i, t}^{I M, s s}$, saves $a_{i, t+1}^{I M, s s}$, works $h_{i, t}^{I M, s s}$ hours, receives dividends $d_{i, t}^{I M, s s}$ and pays taxes/transfers $T_{i, t}^{I M, s s}$, such that aggregate consumption is

$$
C_{s s}^{I M}=\int c_{i, t}^{I M, s s} d i
$$


and aggregate hours are

$$
H_{s s}^{I M}=\int h_{i, t}^{I M, s s} d i .
$$

Aggregate tax revenue is

$$
T_{s s}^{I M}=\int T_{i, t}^{I M, s s} d i,
$$

which balances the government budget constraint

$$
T_{s s}^{I M}=b_{s s} r_{s s}^{I M} .
$$

To understand how the aggregate consumption demand in the incomplete markets model differs from one with complete markets, it is useful to start by considering the behavior of each individual household. Consider the following experiment: each household in the incomplete markets model obtains the same percentage change in hours, wages and dividends as in the complete markets model. Furthermore, apply the same percentage change in the real interest rate and adjust the tax system to balance the budget at each point in time holding the real amount of government debt constant. Households thus obtain a wage

$$
w_{t}^{I M, F G}=\gamma_{t}^{w} w_{s s}^{I M},
$$

a gross real interest rate

$$
R_{t}^{I M, F G}=\gamma_{t}^{R} R_{s s}^{I M},
$$

obtain dividend payment

$$
d_{t}^{I M, F G}=\gamma_{t}^{d} d_{s s}^{I M},
$$

work

$$
h_{i, t}^{I M, F G}=\gamma_{t} h_{i, t}^{I M, s s}
$$


hours and pay taxes

$$
T_{i, t}^{I M, F G}
$$

such that aggregate taxes equal

$$
T_{t}^{I M, F G}=\int T_{i, t}^{I M, F G} d i
$$

and balance the government budget (at constant steady-state real government debt $b_{s s}$ )

$$
b_{s s} R_{t}^{I M, F G}-T_{t}^{I M, F G}=b_{s s} .
$$

Here, we leave the change in the individual tax payment function, $T_{i, t}^{I M, F G}$, unrestricted to keep the theory as general as possible, which allows us to consider different specifications in the quantitative applications below.

Given this new sequence of income and prices, each household $i$ optimally chooses a new consumption path $c_{i, t}^{I M, F G}$. Aggregating yields the aggregate demand in the experiment

$$
C_{t}^{I M, F G}=\int c_{i, t}^{I M, F G} d i
$$

This is the aggregate demand in the incomplete markets model when households face the same changes in income and prices as in the complete markets model. This is a partial equilibrium experiment since it uses complete markets prices, which are not adjusting to clear markets in the incomplete markets model. It is important to note, however, that all prices and the income households receive change - not only the real interest rate. This is important since those changes have distributional consequences that matter in incomplete markets models but not in complete markets models. If markets were complete and households faced these sequences of income and prices, then the aggregate consumption demand response would coincide with the complete markets case, $C_{t}^{I M, F G}=\gamma_{t} C_{s s}^{I M}$.

Due to distributional effects, typically $C_{t}^{I M, F G} \neq \gamma_{t}^{C} C_{s s}^{I M}$. To build intuition for the full general equilibrium response it is instructive to consider whether or not the partial equilibrium aggregate demand from the incomplete markets model experiments exceeds aggregate demand scaled up by the same percentage deviation as in complete markets. 
The idea is as follows. Suppose that $C_{t}^{I M, F G}>\gamma_{t} C_{s s}^{I M}$. Since $\gamma_{t}^{C} C_{s s}^{I M}=\gamma_{t} H_{s s}^{I M}=: H_{t}^{I M, F G}$, this means that aggregate demand exceeds aggregate supply given complete markets prices and income,

$$
C_{t}^{I M, F G}>\gamma_{t} H_{s s}^{I M}=H_{t}^{I M, F G}
$$

This inequality (which in complete markets would be an equality) now suggests, using standard Keynesian-cross logic, where the general equilibrium outcome is likely to be. Since output is demand determined, aggregate demand exceeding aggregate supply means that firms have to increase labor demand to satisfy the excess demand. This higher labor demand means higher income and higher consumption which again requires firms to hire more labor. The process continues until supply equals demand in equilibrium ${ }^{3}$. This reasoning suggest that the equilibrium level of consumption and hours will be higher than $H_{t}^{I M, F G}=\gamma_{t}^{C} C_{s s}^{I M}$.

The same logic but with opposite signs applies if

$$
C_{t}^{I M, F G}<\gamma_{t} H_{s s}^{I M}=H_{t}^{I M, F G}
$$

The lack of demand leads to a downwards adjustment of hours until eventually the lower level of equilibrium consumption and hours is reached.

We now show theoretically that $C_{t}^{I M, F G}$ can exceed or fall short of supply in this partial equilibrium experiment and we explore the reasons why and when this occurs. Next, we will confirm that this finding carries over to general equilibrium using a quantitative example, hence confirming that forward guidance can be more or less powerful in incomplete than in complete markets models.

To understand aggregate demand $C_{t}^{I M, F G}$, we start with the consumption demand $c_{i, t}^{I M, F G}$ of individual $i$ and consider why it differs from $\gamma_{t}^{C} c_{i, t}^{I M, s s}$. If every household increased individual consumption as much (in percentage terms) as the complete markets agents, $c_{i, t}^{I M, F G}=\gamma_{t} c_{i, t}^{I M, s s}$, aggregate demand would do the same, $C_{t}^{I M, F G}=\gamma_{t} C_{s s}^{I M}$, and demand would equal supply. In this knife-edge case, the complete markets and the incomplete markets equilibrium would coincide. Due to redistribution this is in general not the case and $c_{i, t}^{I M, F G}-\gamma_{t} c_{i, t}^{I M, s s} \neq 0$. This

\footnotetext{
${ }^{3}$ Of course, in general equilibrium prices will also adjust. However, the presence of rigidities in prices will prevent the full equilibrium adjustment happening through prices alone.
} 
difference arises since the relative income change $\Delta_{i, t}$ is different for different individuals and can be decomposed as

$$
\begin{aligned}
\Delta_{i, t} & =\underbrace{\left(\gamma_{t}^{w} \gamma_{t}-1\right) w_{s s}^{I M} s_{i, t} h_{i, t}^{I M, s s}}_{\Delta \text { Earnings }}+\underbrace{\left(\gamma_{t}^{d}-1\right) d_{i, t}^{I M, s s}}_{\Delta \text { Dividend Payments }}-\underbrace{\left(\gamma_{t}-1\right) c_{i, t}^{I M, s s}}_{\Delta \text { CM-consumption }} \\
& -\underbrace{\left(T_{i, t}^{I M, F G}-T_{i, t}^{I M, s s}\right)}_{\Delta \text { Tax Payments }}+\underbrace{a_{i, t}^{I M, s s}\left(\gamma_{t}^{R}-1\right) R_{s s}^{I M}}_{\Delta \text { Asset Income }},
\end{aligned}
$$

The earnings in the complete markets equilibrium change by $\left(\gamma_{t}^{w} \gamma_{t}-1\right)$ and so too do the earnings here. The path of dividends changes by $\left(\gamma_{t}^{d}-1\right)$ so that households now receive different dividends. We subtract the term $\left(\gamma_{t}-1\right) c_{i, t}^{I M, s s}$ as this is the income that would be spent if household $i$ behaved as in the complete markets model and increased consumption by $\gamma_{t}-1$. This allows us to compare the demand in the two different environments as $\Delta_{i, t}$ describes the income redistribution relative to the complete markets income/consumption changes. Finally, households have to make different tax payments and their return on assets changes as well. Note that we use households' steady-state assets $a_{i, t}^{I M, s s}$ and do not allow for a re-optimization in response to the counterfactual income redistribution induced by using complete markets prices when defining $\Delta_{i, t}$, which is exogenous to households. In particular, $\Delta_{i, t}$ does not include a household's consumption choices $c_{i, t}^{I M, F G}$ as those are the result of household's optimization taking as given complete markets prices and income changes.

We now show that $\Delta_{i, t}$ is just a redistribution so that it integrates to zero across agents. The government budget constraint implies that

$$
\begin{aligned}
& \int\left(T_{i, t}^{I M, F G}-T_{i, t}^{I M, s s}\right) d i-\int a_{i, t}^{I M, s s}\left(R_{t}^{I M, F G}-R_{s s}^{I M}\right) d i \\
= & \left(T_{t}^{I M, F G}-T_{s s}^{I M}\right)-b_{s s}\left(R_{t}^{I M, F G}-R_{s s}^{I M}\right) \\
= & \left(T_{t}^{I M, F G}-b_{s s}\left(R_{t}^{I M, F G}-1\right)\right)-\left(T_{s s}^{I M}-b_{s s}\left(R_{s s}^{I M}-1\right)\right) \\
= & 0,
\end{aligned}
$$

reflecting the fact that fiscal policy is just redistributive here. Using the fact that output is equal to earnings plus dividends, integrating the change in earnings and dividend payments 
yields

$$
\begin{aligned}
\left(\gamma_{t}-1\right) H_{s s}^{I M} & =\left(\gamma_{t}^{w} \gamma_{t}-1\right) w_{s s}^{I M} H_{s s}^{I M}+\left(\gamma_{t}^{d}-1\right) d^{I M, s s} \\
& =\int\left(\gamma_{t}^{w} \gamma_{t}-1\right) w_{s s}^{I M} h_{i, t}^{I M, s s} d i+\int\left(\gamma_{t}^{d}-1\right) d_{i, t}^{I M, s s} d i
\end{aligned}
$$

so that

$$
\begin{aligned}
\int \Delta_{i, t} d i & =\underbrace{\left(\gamma_{t}-1\right) H_{s s}^{I M}}_{\Delta \text { Earnings }+\Delta \text { Dividends }}-\underbrace{\int\left(\gamma_{t}-1\right) C_{s s}^{I M} d i}_{\Delta \text { CM-consumption }}+\underbrace{0}_{\Delta \text { Taxes }+\Delta \text { Asset Income }} \\
& =0,
\end{aligned}
$$

echoing the fact that $\Delta_{i, t}$ just captures redistribution across households as a deviation from hypothetical complete markets behavior. In other words, in the absence of idiosyncratic risk (and thus trivially complete markets), aggregate demand would equal complete markets aggregate demand. However, this is not the case and this incompleteness leads to heterogeneity in the marginal propensity to consume. Define $M P C_{i, t}$ as this propensity of household $i$ at time $t$ which allows us to approximate the consumption choice of household $i$ at time $t$ as ${ }^{4}$

$$
c_{i, t}^{I M, F G} \approx \gamma_{t} c_{i, t}^{I M, s s}+M P C_{i, t} \Delta_{i, t}
$$

and the aggregate demand as

$$
C_{t}^{I M, F G} \approx \gamma_{t} C_{t}^{I M, s s}+\int M P C_{i, t} \Delta_{i, t} d i
$$

Let $\overline{M P C}_{t}:=\int M P C_{i, t} d i$ be the average MPC, so that

$$
\int M P C_{i, t} \Delta_{i, t} d i=\int\left(M P C_{i, t}-\overline{M P C}_{t}\right) \Delta_{i, t} d i
$$

is the "covariance" since $\int \Delta_{i, t} d i=0$. We can therefore use the sign of this covariance, $\operatorname{cov}\left(M P C_{i, t}, \Delta_{i, t}\right)$, to determine whether our experiment delivers an excess or a shortfall of

\footnotetext{
${ }^{4}$ Note that $M P C_{i, t}$ is an equilibrium object which is specific to the experiment we are considering and that the consumption response depends on the all aspects of the experiment. For example, we suppress the dependence on future income so that we only obtain an approximation that, however, is sufficiently good to explain our findings. For analyses which fully take the dynamic interactions into account, see Auclert et al. (2018) and Hagedorn et al. (2018).
} 
demand:

$$
C_{t}^{I M, F G}-H_{t}^{I M, F G} \begin{cases}>0 & \text { if } \operatorname{cov}\left(M P C_{i, t}, \Delta_{i, t}\right)>0 \\ <0 & \text { for } \operatorname{cov}\left(M P C_{i, t}, \Delta_{i, t}\right)<0\end{cases}
$$

The interpretation is straightforward. If $\operatorname{cov}\left(M P C_{i, t}, \Delta_{i, t}\right)>0-$ on average households who receive a high $\Delta_{i, t}$ have a high $M P C_{i, t}$ - then forward guidance redistributes towards highMPC households. This redistribution increases aggregate demand above the supply $H_{t}^{I M, F G}$. In contrast, if $\operatorname{cov}\left(M P C_{i, t}, \Delta_{i, t}\right)<0$ - on average households who receive a high $\Delta_{i, t}$ have a low $M P C_{i, t}$ — then forward guidance redistributes towards low-MPC households. This redistribution reduces aggregate demand below the supply $H_{t}^{I M, F G}$.

Considering two special cases of our environment helps to sharpen our understanding of both the findings in this paper and in the literature.

First, suppose that there is no heterogeneity in MPCs, $M P C_{i, t}=\overline{M P C}_{t}$ as is the case in complete markets models. Then

$$
\operatorname{cov}\left(M P C_{i, t}, \Delta_{i, t}\right)=\int M P C_{i, t} \Delta_{i, t} d i=\overline{M P C}_{t} \int \Delta_{i, t} d i=0 .
$$

As a result, demand in the incomplete and complete markets model is the same. Although there is income heterogeneity in $\Delta_{i, t}$, this does not effect aggregate demand since each household has the same MPC, $\overline{M P C}_{t}$.

Second, if $\Delta_{i, t} \equiv 0$, then once again

$$
\operatorname{cov}\left(M P C_{i, t}, \Delta_{i, t}\right)=\int M P C_{i, t} \Delta_{i, t} d i=\int M P C_{i, t} 0 d i=0
$$

that is demand in the incomplete and complete markets model is again the same since there is no income heterogeneity. This is the scenario considered in Werning (2015). He assumes that the income of each household moves one-to-one with aggregate income and that bonds are in zero net supply. Income includes all types of income - labor, dividend, transfers - so that his assumptions imply $\Delta_{i, t} \equiv 0$. Our finding in this special case coincides with the conclusion of Werning (2015): Forward guidance is equally powerful in incomplete and complete markets.

We now provide quantitative examples which show that the sign of the covariance can either positive or negative depending on the properties of fiscal policy. 
Table I: Parameter Values in McKay et al. (2016)

\begin{tabular}{llc} 
Parameter & Interpretation & Value \\
\hline$\sigma$ & Risk-aversion & 2 \\
$\beta$ & Discount Factor & 0.986 \\
$\varphi$ & Frisch Elasticity & 0.5 \\
$\epsilon$ & Elas. substitution & 6 \\
$\theta$ & Calvo Price revision rate & 0.15 \\
$b$ & Supply of assets & $1.4 \times$ annual GDP \\
\hline
\end{tabular}

\subsection{Quantitative Examples}

In this Section we use the same model, calibration and monetary policies as in McKay et al. (2016) (MNS). We then allow for two different fiscal policies, one identical to the one used in MNS and another one with different redistributive effects.

MNS assume a quarterly income process with three states - $s_{1}, s_{2}, s_{3}$ - which follows an $\operatorname{AR}(1)$ with autoregressive coefficient 0.966 and innovation variance of $0.017 .{ }^{5}$ The disutility of labor is $g(h)=\psi \frac{h^{1+\frac{1}{\varphi}}}{1+\frac{1}{\varphi}} \cdot{ }^{6}$ To make these quantitative examples directly comparable to those in MNS, we now slightly deviate from the model used in the theoretical analysis above and assume, as in MNS, that prices are set as in Calvo (1983), i.e. firms can re-optimize their price with probability $\theta$. Table I summarizes MNS's parameter values which are also used here.

In terms of fiscal policy, MNS assume the real value of debt to be constant, that there are no transfers and that taxes are paid by the highest productivity type $s_{3}$ only. Each households receives an equal share of the dividends $d_{t}$.

To consider the effectiveness of forward guidance at the ZLB, MNS assume perfect foresight and that the discount factor increases for a known number of periods and then reverts back to its steady-state value, such that the ZLB binds for 20 quarters and generates an impact output decline of 4 percent when monetary policy follows a "naive" policy, described next.

\footnotetext{
${ }^{5} \mathrm{MNS}$ use productivity values $\left[s_{1}, s_{2}, s_{3}\right]=[0.4923,1,2.0313]$ so that aggregate productivity, $\sum s \operatorname{Prob}(s)=$ $s_{1} \pi_{1}+s_{2} \pi_{2}+s_{3} \pi_{3}$ exceed the value in the complete markets model which they set to 1 . We keep the transition probabilities but change the incomplete markets productivities to $\left[s_{1}, s_{2}, s_{3}\right]=[0.5,1,1.5]$, so that aggregate productivity is exactly 1 as it is in complete markets. The population weights of groups $1,2,3$ are the same as in MNS and equal $\left(\pi_{1}=0.25, \pi_{2}=0.5, \pi_{3}=0.25\right)$.

${ }^{6}$ We choose $\psi=1$ for incomplete markets as MNS do, but adjust the complete markets value such that aggregate hours are the same in both economies.
} 


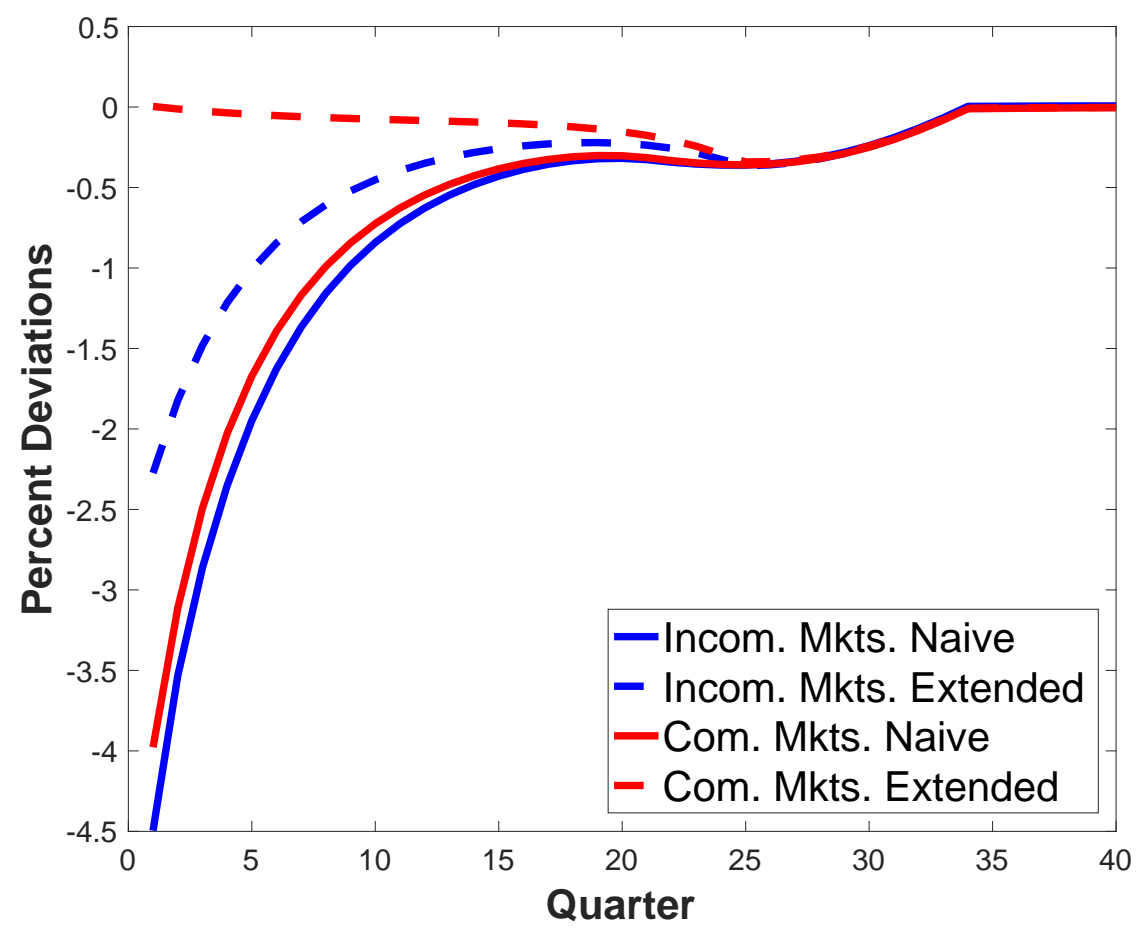

Figure 1: Response of Output to the ZLB Shock: MNS Fiscal Policy

MNS consider two types of monetary policy, which they label the "naive" one and the "extended" one (and we use their terminology in what follows). The naive policy is a standard Taylor rule where the net nominal interest rate $i_{t+1}=\max \left\{0, \bar{r}+\phi \pi_{t}\right\}$, where $\phi=1.5$ and $\bar{r}$ is the steady-state real interest rate, which is fixed at 2 percent annually. In particular, policy implements the Taylor rule as soon as it delivers a positive interest rate. This is policy without any forward guidance. The extended policy — forward guidance policy — differs from the naive policy in this respect as it sets the nominal interest rate to zero for several additional quarters although the Taylor rule already prescribes a positive nominal interest rate. Policy reverts back to the Taylor rule only after these additional quarters. We follow MNS who choose 3 additional quarters of monetary stimulus in order to obtain no initial output drop in the complete markets model.

The idea is then to first compare the effects of the two monetary policies within each model with the interpretation that the difference between the naive and the extended policy is the effect of forward guidance. Second, these effects are compared across models. 


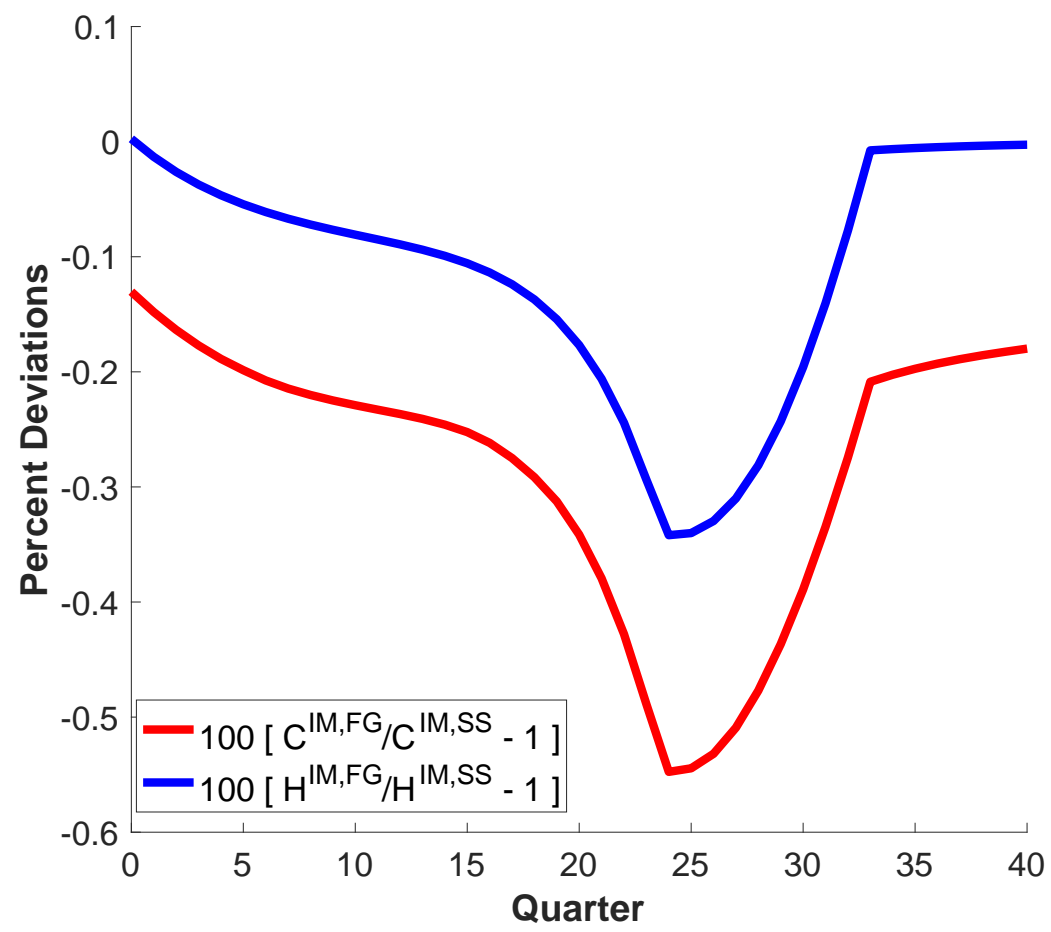

Figure 2: Incomplete Markets \& MNS Fiscal Policy: Aggregate Demand

\subsubsection{Forward Guidance more Powerful in Complete Markets Models}

Figure 1 replicates the main result (Figure 7) in MNS in our slightly modified economy. In this scenario forward guidance is significantly less powerful in incomplete markets models than in complete markets models. While the naive policy delivers an almost identical output path, the results when implementing the extended policy are quite different. In the complete markets case output losses are basically avoided whereas there are substantial output losses in the incomplete markets case, justifying the conclusion that forward guidance is more powerful in complete than in incomplete markets models.

To understand this outcome, Figure 2 shows demand $C_{t}^{I M, F G}$ and supply $H_{t}^{I M, F G}$ in the incomplete markets model for the extended policy when using complete markets model prices, income and the discount factor shock. Remember, that these are not equilibrium objects as we are not using the incomplete markets equilibrium prices. Instead, it is evident that demand falls short of supply so that the general equilibrium adjustment process is correctly expected to lead to lower output in incomplete markets in the extended policy case. Panel (a) of Figure 3 shows the demand of the three income groups, where demand of the income groups $s_{1}$ and 


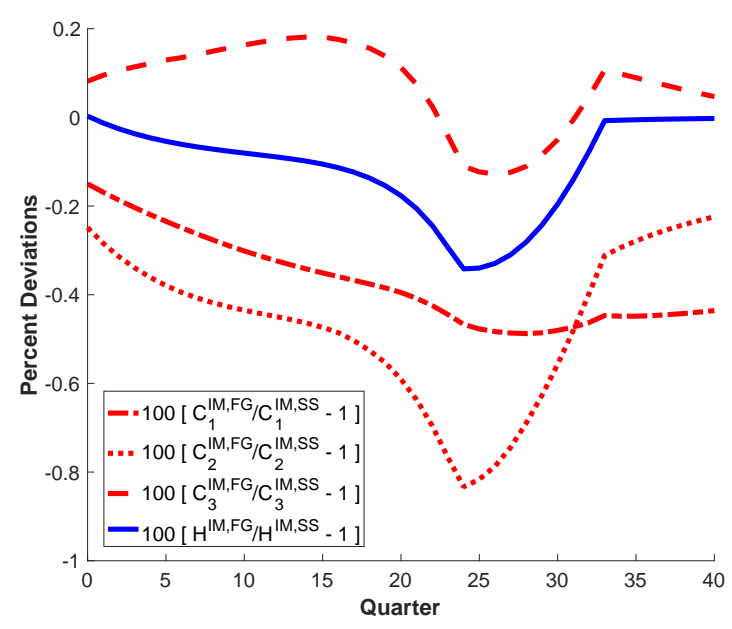

(a) Demand by Productivity

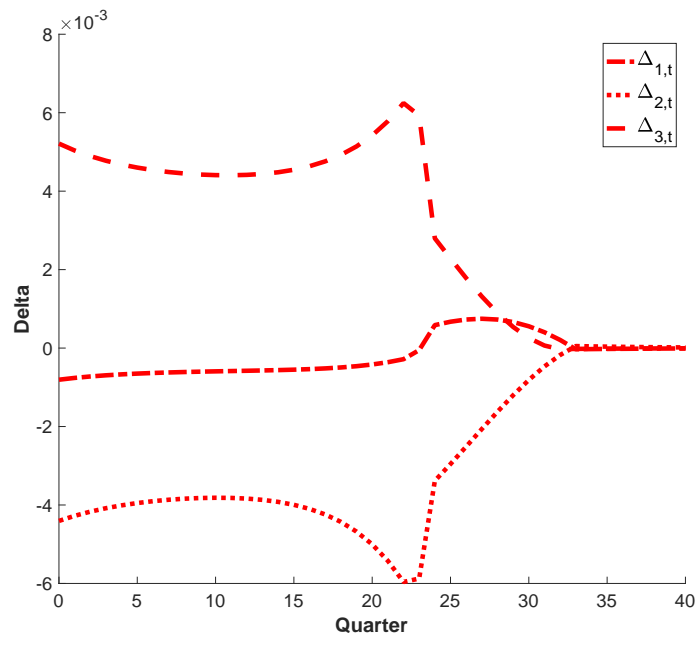

(b) Redistribution $\Delta_{1,2,3}$

Figure 3: Incomplete Markets \& MNS Fiscal Policy: Demand and Redistribution

$s_{2}$ falls more than the increase by $s_{3}$, explaining the overall drop in aggregate demand. To understand what drives these relative differences in demand, panel (b) of Figure 3 shows the income redistribution across the three income groups induced by the policy. Resources are redistributed from groups $s_{1}$ and $s_{2}$ towards group $s_{3}$, explaining why the demand of groups $s_{1}$ and $s_{2}$ fall, but $s_{3}$ rises. The fact that group $s_{3}$ is the low MPC group explains why that group's increase in demand is more than offset by the decline in demand from the other two groups, accounting for the aggregate demand response.

There are two reasons why the interest rate shock leads to a redistribution of wealth away from households with high marginal propensities to consume and toward households with low marginal propensities to consume (which also tend to be the high productivity households). First, the fall in interest rates implies that the tax burden falls, benefiting tax payers. Since it is the high productivity households who pay all the taxes, they are the only beneficiaries of this tax cut. The fall in interest rates hurts asset holders. If high productivity households were to hold all assets, then this loss from lower asset income would have exactly canceled the gain from lower taxes. But since assets are more equally distributed than the tax burden, high productivity households benefit. The other income groups lose since they do not benefit from the tax cut (as they pay no taxes) but now have lower asset income due to lower real interest rates. 


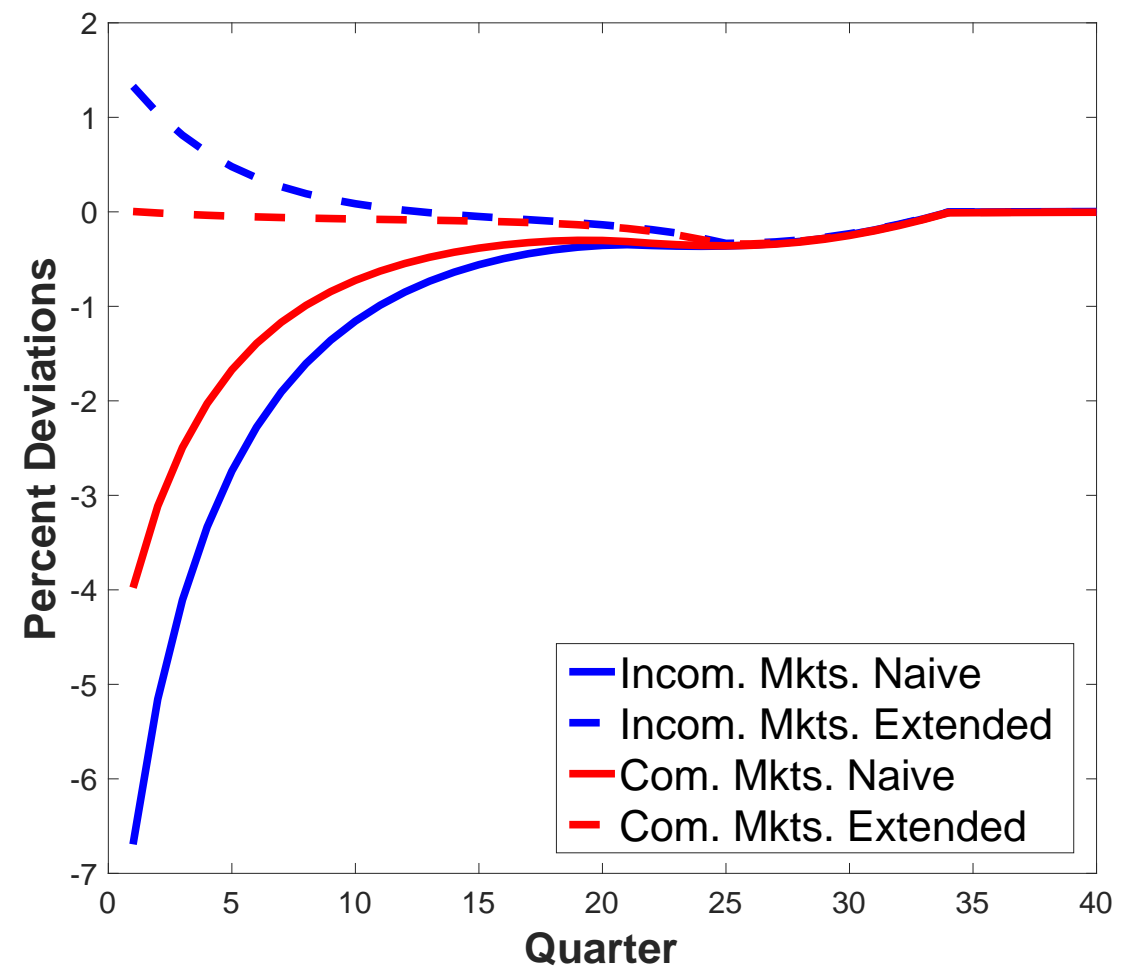

Figure 4: Response of Output to the ZLB Shock: Different Fiscal Policy

A second reason is that an increase in output causes wages to rise and dividends to fall when moving from the naive to the extended policy. Given the equal distribution of dividends in MNS (all income groups receive the same amount), all income groups experience the same loss from a fall in dividends. But the gain from higher wages is larger for high productivity households, who also tend to have low MPCs. Thus, high productivity households benefit relative to low productivity households.

\subsubsection{Forward Guidance more Powerful in Incomplete Markets Models}

We now make one change to the previous model. We assume a different tax policy and partly shift the tax burden from high income households (productivity $s_{3}$ ) towards lower income groups with productivity $s_{1}, s_{2}$ (recall previously that $s_{3}$ households bore the entire tax burden to finance interest expenditures on government debt). Consider a tax function defined by the share of the interest burden paid by households of different productivities $T(s)$. The benchmark model had $T\left(s_{1}\right)=T\left(s_{2}\right)=0$ and $T\left(s_{3}\right) \pi_{3}=1$. Now consider the alternative tax burden: $T\left(s_{1}\right) \pi_{1}=0.14, T\left(s_{2}\right) \pi_{2}=0.5$ and $T\left(s_{3}\right) \pi_{3}=0.36$ where the tax burden is less progressive 


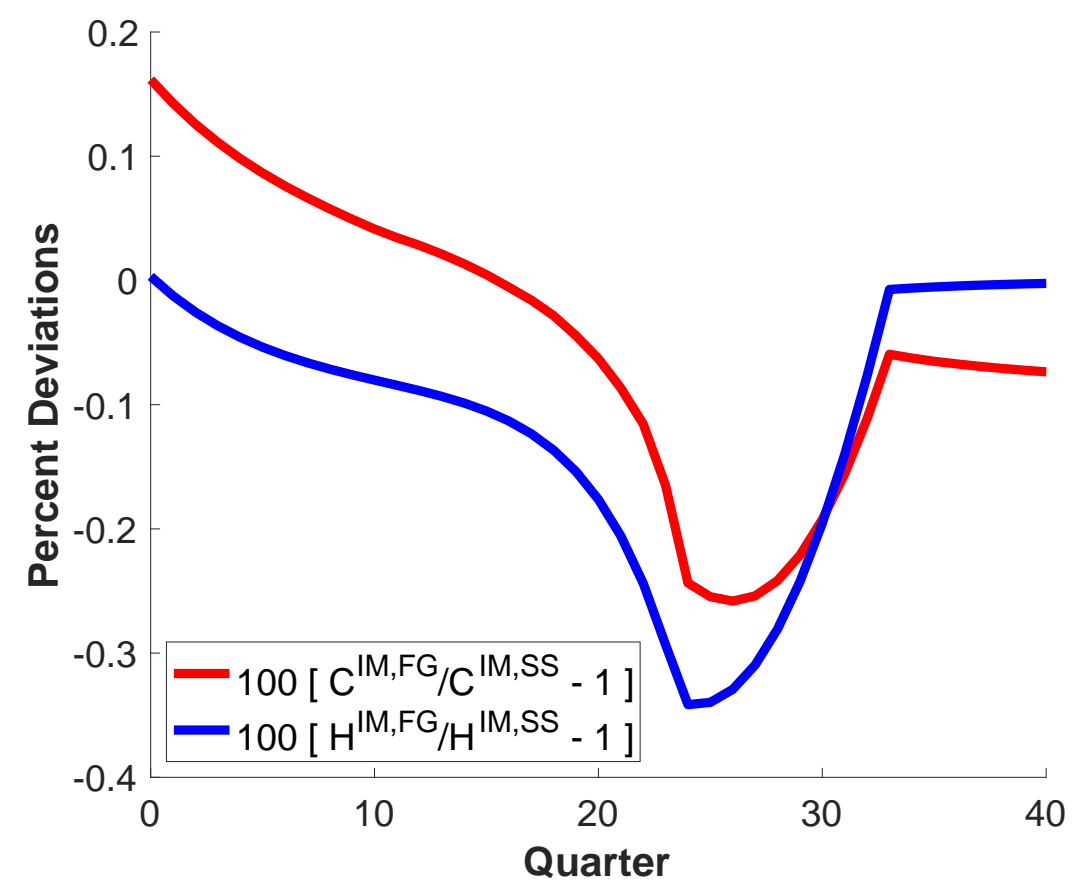

Figure 5: Incomplete Markets \& Different Fiscal Policy: Aggregate Demand

than in the benchmark and shared more equally across all productivity levels. ${ }^{7}$

Figure 4 shows the response of the incomplete markets model to the naive and extended policies under this alternative tax regime. In this scenario forward guidance is more powerful in incomplete markets models than in complete markets models. While the naive policy delivers a larger output loss when markets are incomplete, the results when implementing the extended policy are reversed. In the complete markets case output losses are basically avoided whereas there are now even substantial output gains in the incomplete markets case, leading to the conclusion that forward guidance is more powerful in incomplete than in complete markets models when we use the alternative tax policy.

To understand this result, Figure 5 shows demand $C_{t}^{I M, F G}$ and supply $H_{t}^{I M, F G}$ in the incomplete markets model for the extended policy when using complete markets model prices, income and the discount factor shock. Demand clearly exceeds supply so that the general equilibrium adjustment process is correctly expected to lead to higher output in incomplete markets in the extended policy case. Panel (a) of Figure 6 shows the demand of the three income groups. Demand of income groups $s_{1}$ and $s_{2}$ increases more than the decline from $s_{3}$,

\footnotetext{
${ }^{7}$ The population shares of groups $s_{1}, s_{2}, s_{3}$ are $\left(\pi_{1}, \pi_{2}, \pi_{3}\right)=(0.25,0.5,0.25)$.
} 


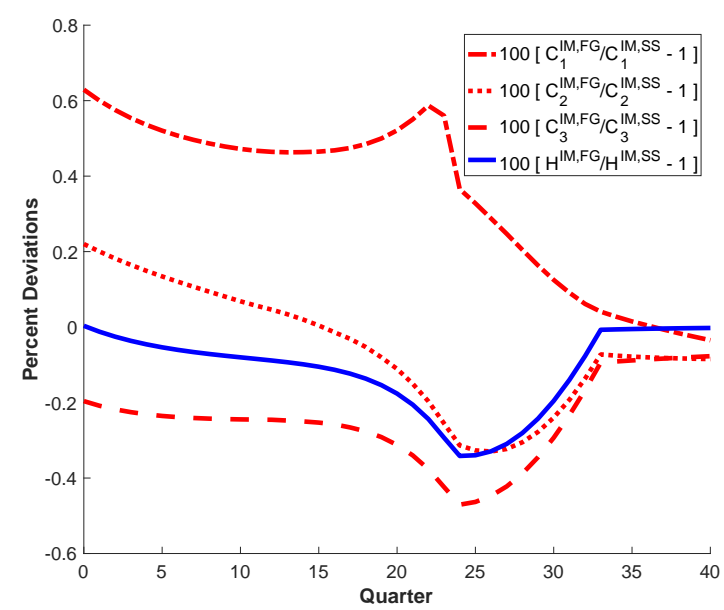

(a) Demand by Productivity

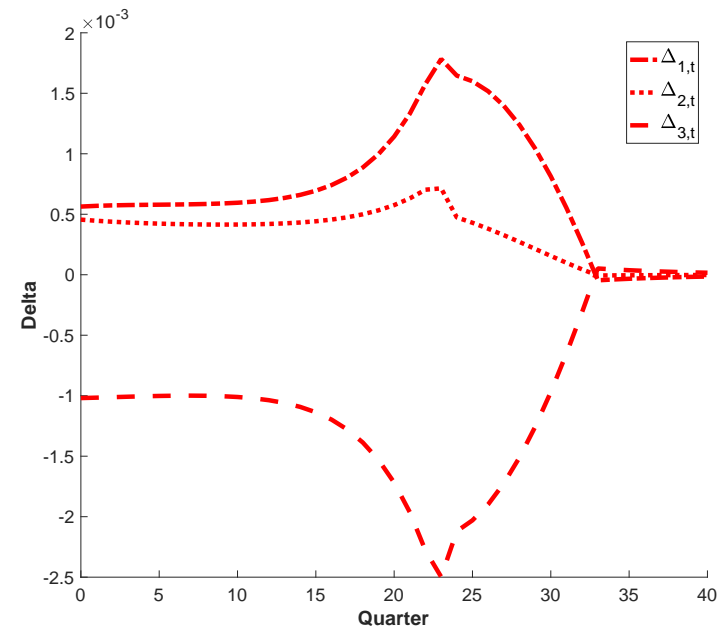

(b) Redistribution $\Delta_{1,2,3}$

Figure 6: Incomplete Markets \& Different Fiscal Policy: Demand and Redistribution

explaining the rise in aggregate demand. Correspondingly, panel (b) of Figure 6 shows the income redistribution between the three income groups. The policy redistributes from group $s_{3}$ towards groups $s_{1}$ and $s_{2}$, consistent with the sign of the demand of the three groups and, since the $s_{3}$ group has low MPC, also consistent with the aggregate demand response.

The different conclusion about the power of forward guidance is due to the redistribution induced by the changes in wages and real interest rates as shown in Figure 7 which in turn are a result of policy. Now the drop in real interest rates (as a result of the policy) leads to a redistribution of wealth towards low productivity households with high marginal propensities to consume. Since all households are taxpayers, all households benefit from the tax reduction. Therefore now all households benefit from lower taxes (due to lower real interest rates) and all households suffer from lower asset income (due to lower real interest rates). To make our point about the power of forward guidance, in this experiment we have chosen the tax policy such that high productivity households lose and low productivity households gain. Due to the higher MPC of low productivity households, aggregate demand increases.

\section{Forward Guidance in a Quantitative Model}

We now quantitatively assess the effects of forward guidance using an enhanced model as in Hagedorn et al. (2018). 


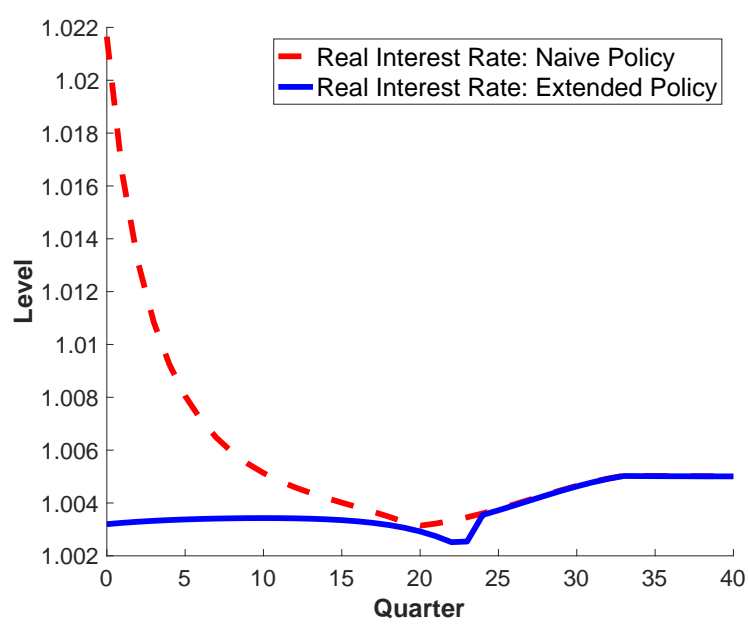

(a) Real Interest Rate

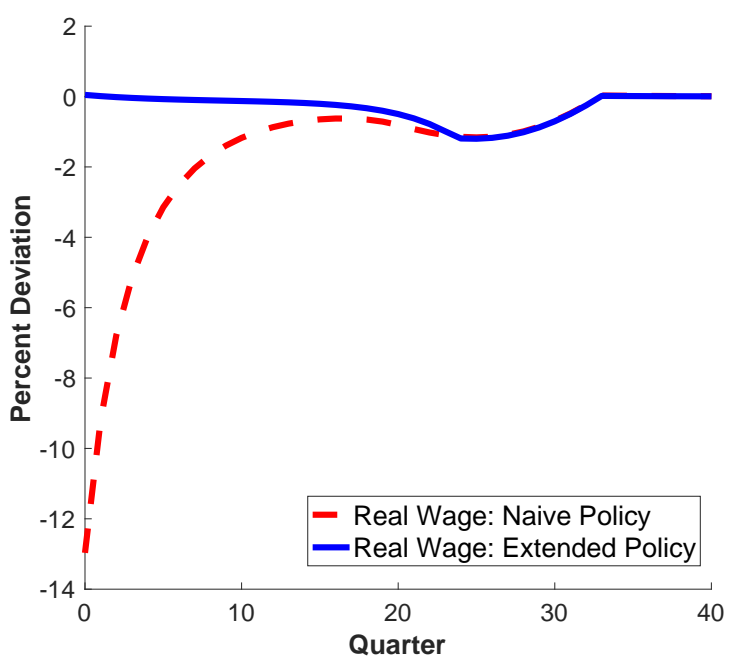

(b) Real Wage

Figure 7: Complete Markets Real Interest Rate and Wage: Naive and Extended Policy

\subsection{Enhanced Model}

We extend the basic model in Section 2 by incorporating rigid wages, nominal government transfers, nominal government bonds and nominal taxes, and fixed costs paid by intermediategood firms.

\subsubsection{Wage Setting}

To allow for sticky wages we follow the literature and assume that each household $i$ provides differentiated labor services, $h_{i t}$. These differentiated labor services are transformed by a representative, competitive labor recruiting firm into an aggregate effective labor input, $H_{t}$, using the following technology:

$$
H_{t}=\left(\int_{0}^{1} s_{i t}\left(h_{i t}\right)^{\frac{\epsilon_{w}-1}{\epsilon_{w}}} d i\right)^{\frac{\epsilon_{w}}{\epsilon_{w}-1}},
$$

where $\epsilon_{w}$ is the elasticity of substitution across labor services.

A union sells households labor services to the labor recruiter, which given aggregate labor demand $H_{t}$ by the intermediate goods sector, minimizes costs

$$
\int_{0}^{1} W_{i t} s_{i t} h_{i t} d i
$$


implying a demand for the labor services of household $j$ :

$$
h_{i t}=h\left(W_{i t} ; W_{t}, H_{t}\right)=\left(\frac{W_{i t}}{W_{t}}\right)^{-\epsilon_{w}} H_{t}
$$

where $W_{t}$ is the (equilibrium) nominal wage which can be expressed as

$$
W_{t}=\left(\int_{0}^{1} s_{i t} W_{i t}^{1-\epsilon_{w}} d i\right)^{\frac{1}{1-\epsilon_{w}}}
$$

The union sets a nominal wage $\hat{W}_{t}$ for an effective unit of labor (so that $W_{i t}=\hat{W}_{t}$ ) to maximize profits subject to wage adjustment costs modeled similarly to the price adjustment costs in Rotemberg (1982). These adjustment costs are proportional to idiosyncratic productivity $s_{i t}$, are measured in units of aggregate output, and are given by a quadratic function of the change in wages above and beyond steady state wage inflation $\bar{\Pi}^{w}$,

$\Theta\left(s_{i t}, W_{i t}=\hat{W}_{t}, W_{i t-1}=\hat{W}_{t-1} ; H_{t}\right)=s_{i t} \frac{\theta_{w}}{2}\left(\frac{W_{i t}}{W_{i t-1}}-\bar{\Pi}^{w}\right)^{2} H_{t}=s_{i t} \frac{\theta_{w}}{2}\left(\frac{\hat{W}_{t}}{\hat{W}_{t-1}}-\bar{\Pi}^{w}\right)^{2} H_{t}$.

The union's wage setting problem is to maximize ${ }^{8}$

$$
\begin{aligned}
V_{t}^{w}\left(\hat{W}_{t-1}\right) & \equiv \max _{\hat{W}_{t}} \int\left(\frac{s_{i t}\left(1-\tau_{t}\right) \hat{W}_{t}}{P_{t}} h\left(\hat{W}_{t} ; W_{t}, H_{t}\right)-\frac{g\left(h\left(\hat{W}_{t} ; W_{t}, H_{t}\right)\right)}{u^{\prime}\left(C_{t}\right)}\right) d i \\
& -\int s_{i t} \frac{\theta_{w}}{2}\left(\frac{\hat{W}_{t}}{\hat{W}_{t-1}}-\bar{\Pi}^{w}\right)^{2} H_{t} d i+\frac{1}{1+r_{t}} V_{t+1}^{w}\left(\hat{W}_{t}\right)
\end{aligned}
$$

where $C_{t}$ is aggregate consumption. Some algebra (see the appendix) yields, using $h_{i t}=H_{t}$ and $\hat{W}_{t}=W_{t}$ and defining the real wage $w_{t}=\frac{W_{t}}{P_{t}}$, the wage inflation equation

$\theta_{w}\left(\pi_{t}^{w}-\bar{\Pi}^{w}\right) \pi_{t}^{w}=\left(1-\tau_{t}\right)\left(1-\epsilon_{w}\right) w_{t}+\epsilon_{w} \frac{g^{\prime}\left(h\left(\hat{W}_{t} ; W_{t}, H_{t}\right)\right)}{u^{\prime}\left(C_{t}\right)}+\frac{1}{1+r_{t}} \theta_{w}\left(\pi_{t+1}^{w}-\bar{\Pi}^{w}\right) \pi_{t+1}^{w} \frac{H_{t+1}}{H_{t}}$.

The wage adjustment process does not involve actual costs, but optimal choices are made is asif those costs were actually present. This is the same assumption as for the price adjustment process, and for similar reasons: to avoid that wage adjustment costs become a non-trivial fraction of output in the liquidity trap.

\footnotetext{
${ }^{8}$ Equivalently one can think of a continuum of unions each setting the wage for a representative part of the population with $\int s=1$ at all times.
} 


\subsubsection{Government}

The government obtains revenue from taxing labor income and profits as well as issuing bonds. Household labor income $w s h$ is taxed progressively with a nominal lump-sum transfer $\tilde{T}_{t}$ and a proportional tax $\tau_{t}$ :

$$
T_{t}\left(w_{t} s_{t} h_{t}\right)=-\tilde{T}_{t}+\tau_{t} P_{t} w_{t} s_{t} h_{t}
$$

Note that we slightly abuse the notation by using $T_{t}$ to denote nominal taxes here whereas it was denoting real taxes above. The government issues nominal bonds denoted by $B^{g}$, with negative values denoting government asset holdings and fully taxes profits away using a lumpsum, and thus non-distortionary, profit tax and obtaining nominal revenue $P_{t} d_{t}$. The government uses the revenue to finance interest payments on bonds and transfers to households. The government budget constraint is therefore given by:

$$
B_{t+1}^{g}=\left(1+i_{t}\right) B_{t}^{g}-P_{t} d_{t}-\int T_{t}\left(w_{t} s_{t} h_{t}\right) d \Omega_{t}
$$

\subsubsection{Fixed Cost}

Intermediate good firms have to pay a fixed $\operatorname{cost} \Phi$ such that their equilibrium real profit is

$$
d_{t}=Y_{t}-w_{t} Y_{t}-\Phi
$$

\subsubsection{Equilibrium}

The definition of a competitive equilibrium follows that from Section 2, with the following modifications. In addition to previously listed conditions, we now require that wages are set optimally by middlemen. The government budget constraint is now (42) and the market clearing conditions now read:

For all $\Omega_{t} \in \mathcal{M}$ :

$$
\begin{aligned}
B_{t+1}^{g} / P_{t+1} & =\int a_{t+1}\left(a_{t}, s_{t}\right) d \Omega_{t}, \\
H_{t} & =\int s h_{t} d \Omega_{t}=\int n_{j t} d j, \\
Y_{t}=H_{t} & =\int c\left(a_{t}, s_{t}\right) d \Omega_{t}+\Phi .
\end{aligned}
$$




\subsection{Calibration}

To quantitatively assess the effects of forward guidance we now calibrate the model.

Preferences Households have separable preferences over labor and constant relative risk aversion preferences for consumption. We set the risk-aversion parameter, $\sigma$, equal to 2 . We choose the discount factor, $\beta$, to target a quarterly risk-free rate of $50 \mathrm{BP}$. We assume the functional form for $g$ :

$$
g(h)=\psi \frac{h^{1+\frac{1}{\varphi}}}{1+\frac{1}{\varphi}} .
$$

We set the Frisch elasticity, $\varphi=0.5$, following micro estimates. We choose $\psi=0.36$ such that in steady state $h=1.2$ (we normalize earnings $h w=1$ ).

Productivity Process We follow Krueger et al. (2016) who use data from the Panel Survey of Income Dynamics to estimate a stochastic process for labor productivity. They estimate that log income consists of a persistent and transitory component. They estimate that the persistent shock has an annual persistence of 0.9695 and variance of innovations of 0.0384 . The transitory shock is estimated to have variance 0.0522. We follow Krueger et al. (2016) in converting these annual estimates into a quarterly process. We discretize the persistent shock into a seven state Markov chain using the Rouwenhorst method and integrate over the transitory shock using Gauss-Hermite quadrature with three nodes.

Production Technology We choose the elasticity of substitution between intermediate goods, $\epsilon=6$, to match an average markup of $20 \%$. The adjustment cost parameter on prices, $\theta=52$, is chosen to match a slope of the NK Philips curve, $\epsilon / \theta=0.11$ from MNS. We set the firm operating cost $\Phi$ equal to $100 \%$ of the steady state markup such that steady state profits equal 0\% (Basu and Fernald (1997)). These profits are fully taxed and are distributed to households as lump-sum transfers in the benchmark. We choose the same elasticity of substitution between labor services as for intermediate goods $\epsilon=\epsilon_{w}$, to generate the same markup. In addition, we choose the same adjustment cost parameter on wages as for prices $\left(\theta=\theta_{w}\right)$ such that the slope of the wage Philips curve is also 0.11. 
Table II: Calibrated Parameters

\begin{tabular}{llll} 
Parameter & Interpretation & Internally Calibrated & Value \\
\hline$\sigma$ & Risk-aversion & $\mathrm{N}$ & 2 \\
$\beta$ & Discount Factor & $\mathrm{Y}$ & 0.985 \\
$\varphi$ & Frisch Elasticity & $\mathrm{N}$ & 0.5 \\
$\psi$ & Labor disutility & $\mathrm{Y}$ & 0.36 \\
$\epsilon_{p}$ & Elas. substitution & $\mathrm{N}$ & 6 \\
$\epsilon_{w}$ & Elas. substitution & $\mathrm{N}$ & 6 \\
$\theta_{p}$ & Price adjustment & $\mathrm{N}$ & 52 \\
$\theta_{w}$ & Wage adjustment & $\mathrm{N}$ & 52 \\
$\Phi$ & Firm Fixed Cost & $\mathrm{Y}$ & 0.2 \\
$\tau$ & Labor tax & $\mathrm{N}$ & $25 \%$ \\
$T$ & Transfer & $\mathrm{Y}$ & $22 \%$ of income \\
\hline
\end{tabular}

Government We set the proportional labor income tax, $\tau$ equal to $25 \%$. We set debt to annual GDP to 1.4. Residually, from the government budget constraint this implies that transfers are approximately $22 \%$ of average income.

Monetary Policy For the benchmark specification we assume the same form of the Taylor rule adopted by MNS. However, we set the coefficient on inflation to 0.5.

\subsection{Results}

To consider the effectiveness of forward guidance at the ZLB, we follow McKay et al. (2016) and assume that the discount factor increases for a known number of periods and then reverts back to its steady-state value, such that the ZLB binds for 8 quarters and generates an impact output decline of $4 \%$ percent when monetary policy follows the naive policy.

We consider the same two policy environments as in McKay et al. (2016). A naive policy where monetary policy follows a Taylor rule and an extended - forward guidance - policy where the nominal interest rate is kept at zero for 3 additional periods although the Taylor rule already prescribes a positive value. As in MNS, we also assume perfect foresight.

Figure 8 shows the induced distribution $\Delta_{i, 0}$ in the first period 0 as a function of steady- 
state assets $a_{i, 0}^{I M, s s}$ and productivity $s_{i, 0} \cdot{ }^{9}$ The left panel uses the complete markets prices and incomes of the naive policy and the right panel uses the complete markets prices and incomes of the extended policy. The distribution for the naive policy is as expected. The real interest rate rises and the wage falls when the naive policy prices and income are used, so that $\Delta$ is positive for asset-rich households and falls in productivity, but on net this results in a redistribution towards low-MPC households. This suggests that the naive policy is even less effective in our model than in the corresponding complete markets model.

When using the complete markets extended policy prices and income, the real interest rate decreases and the wage moves only little. These price movements are reflected in the shape of $\Delta$ which falls in assets (since the real interest rate falls) and is basically flat in productivity (since the real wage moves only little), which together results in a redistribution towards highMPC households. This suggests that forward guidance is more effective in our model than in the corresponding complete markets model.

While the distributional consequences are quite different in the two policy scenarios, they are small for the extended policy and quite large for the naive policy, suggesting that the deviations from the complete markets allocation can be substantial in our model. The deviation is expected to be larger in the latter case since the distribution $\Delta$ is larger in the latter case because wages and real interest rates move more without forward guidance.

This reasoning is, however, incomplete as it overlooks that we introduced two key differences in the quantitative model relative to the simpler one in Section 2: wages are sticky and bonds are nominal. The comparison was based on complete markets prices which exhibited large differences between the naive and the extended policies. In our quantitative incomplete markets model this is not the case anymore. Figure 9 shows the results for output, inflation, nominal and real interest rates and nominal and real wages, both for the naive and the extended forward guidance policy. Clearly, the differences between the two policies are very small.

Our main finding is that forward guidance has only a very small impact on output and inflation. On impact, output increases by $0.3 \%$ (from $-4.1 \%$ to $-3.8 \%$ ), and inflation by 15 base points (from $-2.16 \%$ to $-2.01 \%$ ).

\footnotetext{
${ }^{9}$ To take into account that fixed $\operatorname{costs} \Phi>0$ in our model we have to adjust the change in hours $\gamma_{t}^{H}$ by $\frac{\Phi\left(1-\gamma_{t}\right)}{\gamma_{t}^{w} * w_{s s}^{I M} * H_{s s}^{I M}}$ downwards.
} 


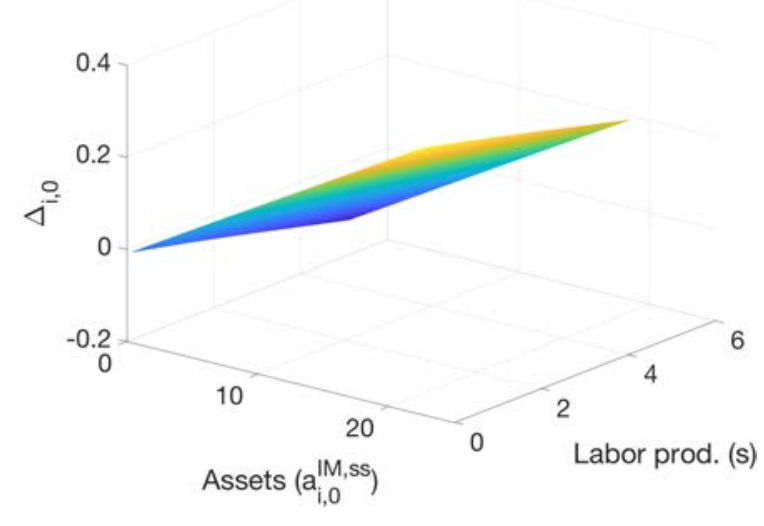

(a) Naive Policy

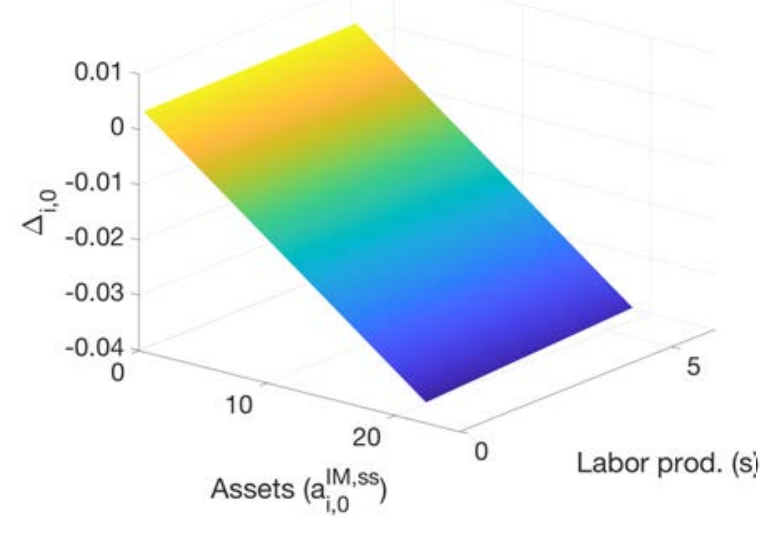

(b) Extended Policy (Forward Guidance)

Figure 8: Redistribution of Income $\Delta_{i, 0}$ using Complete-Markets Prices for Naive/Extended Policy

There are two reasons for the much smaller effect of forward guidance in our incomplete markets model than in the corresponding complete markets model. Both reasons are related to the different response of prices - wages and real interest rates - in the two models. In our model both prices respond very little as a result of forward guidance as shown in Figure 9 whereas there is a sizable response in the complete markets model considered by MNS as we showed in Figure 7.

First, wages respond little since wages are sticky (as opposed to flexible in the MNS). Since wages move little, there is little redistribution of labor income. Furthermore, since productivity is constant, the small movement in wages implies that dividends do not change much either. As a result, there the redistribution induced by the change in dividends is small.

Second, we find that the effect of forward guidance on real interest rates is small. This has two consequences. First, small changes in real interest rates lead to small changes in the intertemporal substitution behavior of households. Second, the small change in real interest rates has only small effects on the government budget and thus on households' tax burden. As a result, the induced redistribution through taxes is small. Figure 10 shows that the redistribution induced by forward guidance relative to the allocation resulting from the naive policy in the first period is quite small. Naive policy allocations and equilibrium prices in our incomoplete markets model are denoted by a superscript $N P$ and the forward guidance 

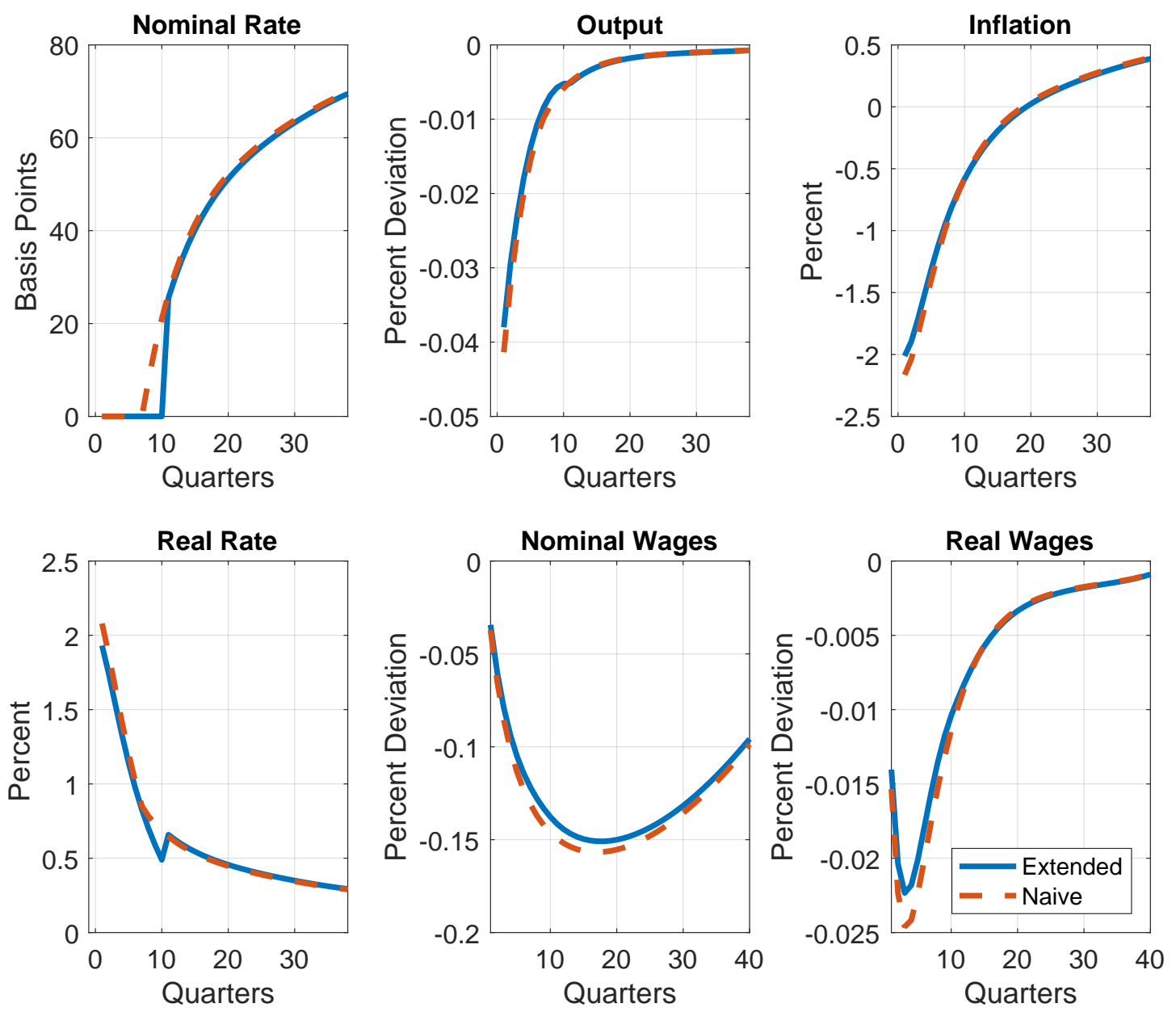

Figure 9: Liquidity Trap without (dashed red lines) and with Forward Guidance (solid blue lines)

equilibrium prices are denoted by a superscript $F G$ :

$$
\Delta_{i, t}^{F G}=\underbrace{\left(w_{t}^{F G}-w_{t}^{N P}\right) s_{i, t} h_{i, t}^{N P}}_{\Delta \text { Earnings }}+\underbrace{d_{i, t}^{F G}-d_{i, t}^{N P}}_{\Delta \text { Dividend Payments }}-\underbrace{\left(T_{i, t}^{F G}-T_{i, t}^{N P}\right)}_{\Delta \text { Tax Payments }}+\underbrace{\left(R_{t}^{F G}-R_{t}^{N P}\right) a_{i, t}^{N P}}_{\Delta \text { Asset Income }},
$$

which is the sum of four components. The first describes the change in earnings of household $i$ when moving from the naive to the forward guidance policy. The second term is the corresponding change in household $i$ 's dividend payments from which we subtract the third term, the change in tax payments. The last term is the change in asset income due to the change in interest rates evaluated using household's asset holdings when the naive policy is implemented, $a_{i, t}^{N P}$. All four terms together, $\Delta_{i, t}^{F G}$, describe the income redistribution when forward guidance instead of the naive policy is implemented. Note, that this is a redistribution between two 


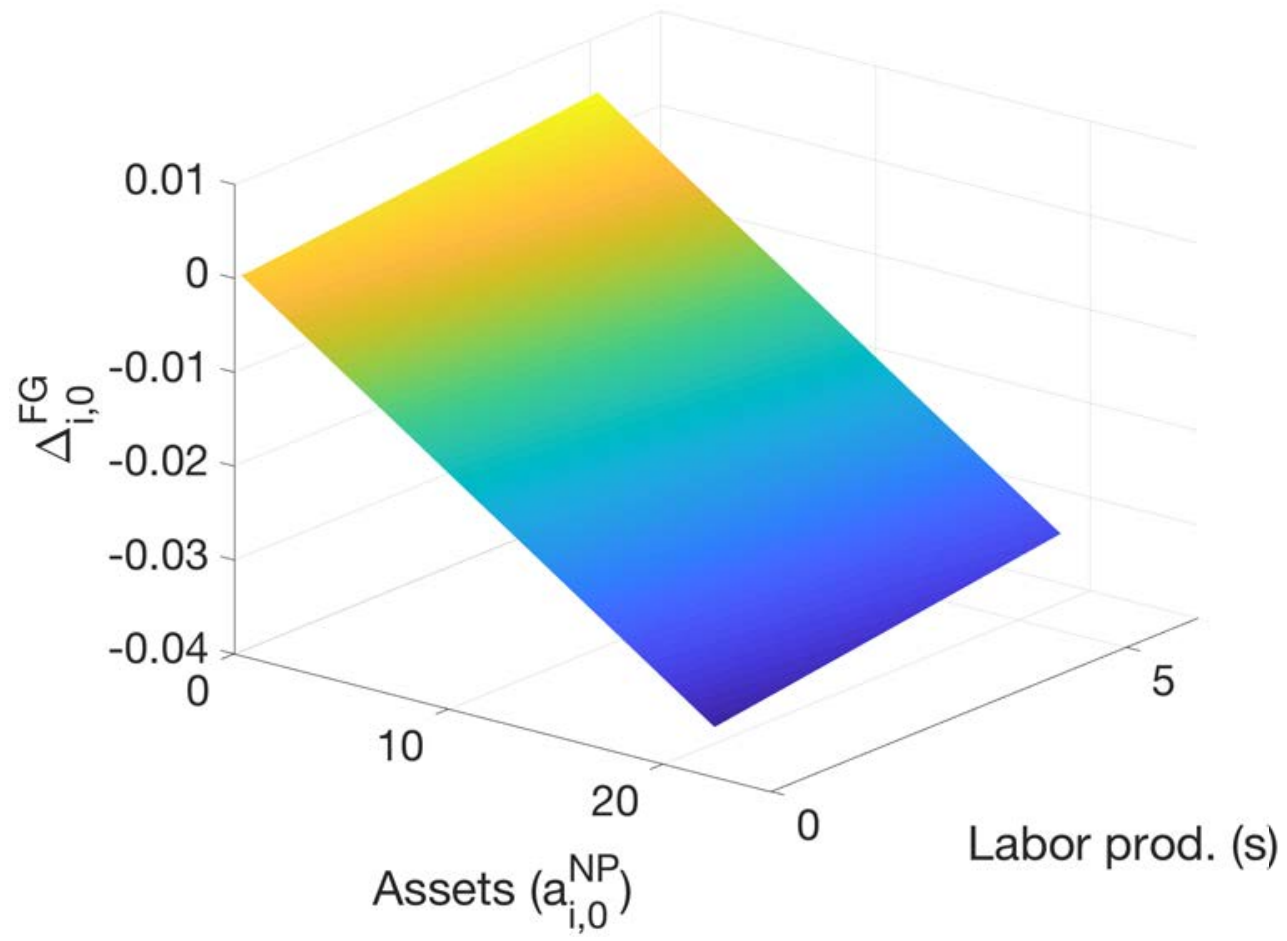

Figure 10: Redistribution of Income $\Delta_{i, 0}^{F G}$ Induced by Forward Guidance

equilibrium allocations in our incomplete markets model and thus does not use any complete markets prices or allocations. Therefore, $\Delta_{i, t}^{F G}$ is not related to $\Delta_{i, t}$, which describes the income redistribution using non-equilibrium complete markets prices and allocations.

Figure 10 shows that forward guidance has only a small effect on intertemporal substitution and on redistribution and as a consequence only a small effect on aggregate consumption and output. Thus, it is not a powerful monetary tool, even in a liquidity trap. It is important to note that these findings are not driven by a general ineffectiveness of monetary policy in our model environment. Contemporaneous changes in monetary policy can be quite potent even when the economy starts off from being in steady state. But the contemporaneous effects of future monetary policy changes are small. To illustrate this point we conduct the following experiment. We lower the nominal interest by 50 base points to 0 for 4 quarters starting at different times and leave the rate at its steady-state value in all other periods. We first consider an immediate cut in rates from periods $1-4$, then from periods $2-5$, and so on until periods 33 - 36. For each of these different horizons of forward guidance we compute the current 


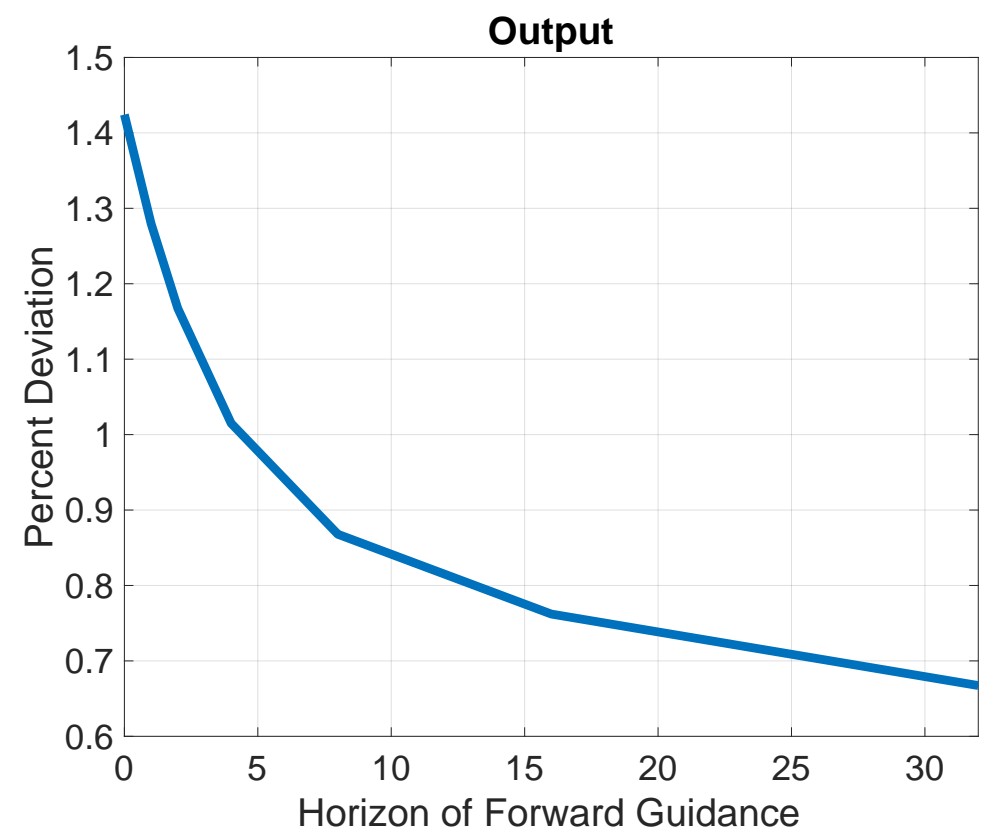

Figure 11: Response of Impact Output by Horizon of Forward Guidance

impact on output and plot it in Figure 11. Typically one might expect that future policy changes have smaller effects than current changes. And indeed, we find that the effectiveness of forward guidance to decrease with its horizon.

\section{Conclusions}

Forward guidance, the communication of future policy actions, is a prominent tool of monetary policy (Plosser, 2013). This is not surprising since it seems important to anchor the expectations of the private sector about the future path of monetary policy as this matters for example for investment, consumption and employment decisions. At this level the meaning of forward guidance is just improved communication of present and future policy decisions. During the Great Recession another aspect was added when forward guidance was discussed as a means to avoid large output losses. It involved the commitment to keep future nominal interest rates at zero although future economic conditions already ask for higher rates, for example because the economy is recovering or inflation is picking up. In standard New Keynesian models such a commitment was found to be very effective in reducing or even avoiding the initial output loss that would otherwise have occurred when the economy moved into a 
liquidity trap (Carlstrom et al., 2015). The effects are so large and sometimes even counterintuitive that this finding was termed the "Forward Guidance Puzzle" since Del Negro et al. (2012).

The follow-up literature has addresses this puzzle along several dimensions. One approach, most prominently taken by McKay et al. (2016) and Werning (2015), is to re-assess forward guidance in incomplete markets models. Both these papers agree that forward guidance is is likely to be an effective monetary tool but disagree about whether forward guidance is different in complete and incomplete markets models. Whereas McKay et al. (2016) find significant differences and forward guidance to be less effective in incomplete markets models, Werning (2015) reaches the opposite conclusion that there is no difference.

This paper makes two main contributions to this literature. First, we explain theoretically and show quantitatively why the literature has reached opposite conclusions about the power of forward guidance in complete and incomplete markets models. Our analysis shows that the difference is due to different assumptions on the distribution of income, profits and tax policies. For example, if forward guidance redistributes towards high marginal propensity to consume (MPC) households then it is more effective in incomplete markets models as this redistribution stimulates aggregate demand more than in does in complete markets models. If on the other hand the redistribution is from high MPC households to low MPC households then forward guidance is less effective in incomplete markets models as demand is depressed relative to complete markets models.

Our second contribution is to re-assess forward guidance in an empirically grounded quantitative model. We find that this policy is not an effective tool of monetary policy as promises of future interest rates have only negligible effects on current output and employment. To understand this result, recall that forward guidance operates through a distributional channel and an intertemporal substitution channel. We find that both of these channels are not triggered to an important extent by the forward guidance. Consider first the distributional effects. We conduct our analysis in a model with a significant amount of individual heterogeneity in income and wealth which resembles the extent of inequality in the data. The consequence is a large heterogeneity in MPCs and that redistribution can have large demand effects. Thus it is not the absence of redistribution channels which explains our findings, but the lack of the redistribution induced by forward guidance. First, with the empirically relevant degree of 
wage rigidities, wages move relatively little, implying only minor redistribution across workers with different productivity levels. Relatively stable wages imply that firms' profits are also stable so there is only little redistribution across individuals with heterogeneous asset holdings through movements in dividends. Moreover, the theoretical arguments in Hagedorn (2016, 2018) suggest that the effects of forward guidance on the real interest rates are dampened in an incomplete markets model. Our quantitative analysis reveals that the dampening is very substantial so that real interest rates move only very little. This implies little redistribution through the tax and transfer system as there is only a small impact on the government budget. Taken together, these findings imply little overall redistribution and little effect on aggregate demand coming through distributional channels. This leaves only the intertemporal substitution channel through which forward guidance can have significant economic effects. But this channel is also not triggered in our incomplete markets model because we find forward guidance to have only small effects on real interest rates. Thus, forward guidance does not appear to be an effective monetary policy tool, even in a liquidity trap. 


\section{References}

Aiyagari, S. R. (1994): "Uninsured Idiosyncratic Risk and Aggregate Saving," The Quarterly Journal of Economics, 109, 659-84.

(1995): "Optimal Capital Income Taxation with Incomplete Markets, Borrowing Constraints, and Constant Discounting," Journal of Political Economy, 103, 1158-1175.

Auclert, A., M. Rognlie, And L. Straub (2018): "The Intertemporal Keynesian Cross," Working paper.

Basu, S. and J. G. Fernald (1997): "Returns to Scale in U.S. Production: Estimates and Implications," Journal of Political Economy, 105, 249-283.

Calvo, G. A. (1983): "Staggered Prices in a Utility-Maximizing Framework," Journal of Monetary Economics, 12, 383 - 398.

Carlstrom, C. T., T. S. Fuerst, and M. Paustian (2015): "Inflation and Output in New Keynesian Models with a Transient Interest Rate Peg," Journal of Monetary Economics, 76, $230-243$.

Christiano, L. J., M. Eichenbaum, And C. Evans (2005): "Nominal Rigidities and the Dynamic Effects of a Shock to Monetary Policy," Journal of Political Economy, 113, 1-45.

Del Negro, M., M. Giannoni, and C. Patterson (2012): "The Forward Guidance Puzzle," Federal Reserve Bank of New York Staff Report 574.

Hagedorn, M. (2016): "A Demand Theory of the Price Level," Working paper, University of Oslo.

- (2018): "Prices and Inflation when Government Bonds are Net Wealth," CEPR Discussion Paper No. 12769.

Hagedorn, M., I. ManovskiI, And K. Mitman (2018): "The Fiscal Multiplier," available at http://papers.nber.org/sched/efgw18.

Krueger, D., K. Mitman, And F. Perri (2016): "Macroeconomics and Heterogeneity, Including Inequality," in Handbook of Macroeconomics, second edition, ed. by J. Taylor and H. Uhlig, Elsevier. 
McKay, A., E. Nakamura, And J. Steinsson (2016): "The Power of Forward Guidance Revisited," American Economic Review, 106, 3133-58.

Plosser, C. I. (2013): "Forward Guidance," Prepared for Stanford Institute for Economic Policy Research's (SIEPR) Annual Meeting, Stanford, CA, February 12, 2013.

RotemberG, J. J. (1982): "Sticky Prices in the United States," The Journal of Political Economy, 1187-1211.

Werning, I. (2015): "Incomplete Markets and Aggregate Demand," Working paper. 


\section{APPENDICES}

\section{Derivations and Proofs}

\section{I.1 Derivation Pricing Equation}

The firm's pricing problem is

$V_{t}\left(p_{j t-1}\right) \equiv \max _{p_{j t}} \frac{p_{j t}}{P_{t}} y\left(p_{j t} ; P_{t}, Y_{t}\right)-w_{t}\left(\frac{y\left(p_{j t} ; P_{t}, Y_{t}\right)}{Z_{t}}\right)^{\frac{1}{1-\alpha}}-\frac{\theta}{2}\left(\frac{p_{j t}}{p_{j t-1}}-\bar{\Pi}\right)^{2} Y_{t}+\frac{1}{1+r_{t}} V_{t+1}\left(p_{j t}\right)$

subject to the constraints $n_{j t}=\left(\left(\frac{p_{j t}}{P_{t}}\right)^{-\epsilon} \frac{Y_{t}}{Z_{t}}\right)^{\frac{1}{1-\alpha}}$ and $y\left(p_{j t} ; P_{t}, Y_{t}\right)=\left(\frac{p_{j t}}{P_{t}}\right)^{-\epsilon} Y_{t}$.

Equivalently

$V_{t}\left(p_{j t-1}\right) \equiv \max _{p_{j t}} \frac{p_{j t}}{P_{t}}\left(\frac{p_{j t}}{P_{t}}\right)^{-\epsilon} Y_{t}-w_{t}\left(\left(\frac{p_{j t}}{P_{t}}\right)^{-\epsilon} \frac{Y_{t}}{Z_{t}}\right)^{\frac{1}{1-\alpha}}-\frac{\theta}{2}\left(\frac{p_{j t}}{p_{j t-1}}-\bar{\Pi}\right)^{2} Y_{t}+\frac{1}{1+r_{t}} V_{t+1}\left(p_{j t}\right)$

The FOC w.r.t $p_{j t}$

$(1-\epsilon)\left(\frac{p_{j t}}{P_{t}}\right)^{-\epsilon} \frac{Y_{t}}{P_{t}}+\frac{\epsilon}{1-\alpha} w_{t}\left(\frac{p_{j t}}{P_{t}}\right)^{-\frac{\epsilon}{1-\alpha}-1}\left(\frac{Y_{t}}{Z_{t} P_{t}}\right)^{\frac{1}{1-\alpha}}-\theta\left(\frac{p_{j t}}{p_{j t-1}}-\bar{\Pi}\right) \frac{Y_{t}}{p_{j t-1}}+\frac{1}{1+r_{t}} V_{t+1}^{\prime}\left(p_{j t}\right)=0$

and the envelope condition

$$
V_{t+1}^{\prime}=\theta\left(\frac{p_{j t+1}}{p_{j t}}-\bar{\Pi}\right) \frac{p_{j t+1}}{p_{j t}} \frac{Y_{t+1}}{p_{j t}} .
$$

Combining the FOC and and the envelope condition

$$
\begin{gathered}
(1-\epsilon)\left(\frac{p_{j t}}{P_{t}}\right)^{-\epsilon} \frac{Y_{t}}{P_{t}}+\frac{\epsilon}{1-\alpha} w_{t}\left(\frac{p_{j t}}{P_{t}}\right)^{-\frac{\epsilon}{1-\alpha}-1}\left(\frac{Y_{t}}{Z_{t} P_{t}}\right)^{\frac{1}{1-\alpha}} \\
-\theta\left(\frac{p_{j t}}{p_{j t-1}}-\bar{\Pi}\right) \frac{Y_{t}}{p_{j t-1}}+\frac{1}{1+r_{t}} \theta\left(\frac{p_{j t+1}}{p_{j t}}-\bar{\Pi}\right) \frac{p_{j t+1}}{p_{j t}} \frac{Y_{t+1}}{p_{j t}}=0
\end{gathered}
$$

Using that all firms choose the same price in equilibrium

$$
\begin{aligned}
& (1-\epsilon)+\frac{\epsilon}{1-\alpha} w_{t} Z_{t}^{\frac{1}{\alpha-1}}\left(\frac{Y_{t}}{P_{t}}\right)^{\frac{\alpha}{1-\alpha}} \\
- & \theta\left(\pi_{t}-\bar{\Pi}\right) \pi_{t}+\frac{1}{1+r_{t}} \theta\left(\pi_{t+1}-\bar{\Pi}\right) \pi_{t+1} \frac{Y_{t+1}}{Y_{t}}=0
\end{aligned}
$$




\section{I.2 Derivation Wage Equation}

$$
\Theta\left(s_{j t}, W_{j t}, W_{j t-1} ; Y_{t}\right)=s_{j t} \frac{\theta_{w}}{2}\left(\frac{\hat{W}_{t}}{\hat{W}_{t-1}}-\bar{\Pi}^{w}\right)^{2} H_{t} .
$$

The middleman's wage setting problem is to maximize

$$
\begin{aligned}
& V_{t}^{w}\left(\hat{W}_{t-1}\right) \\
\equiv & \max _{\hat{W}_{t}} \int\left(\frac{s_{i t}\left(1-\tau_{t}\right) \hat{W}_{t}}{P_{t}} h\left(\hat{W}_{t} ; W_{t}, H_{t}\right)-s_{i t} g\left(h\left(\hat{W}_{t} ; W_{t}, H_{t}\right)\right) d i-\int s_{i t} \frac{\theta_{w}}{2}\left(\frac{\hat{W}_{t}}{\hat{W}_{t-1}}-\bar{\Pi}^{w}\right)^{2} H_{t} d i\right. \\
+ & \frac{1}{1+r_{t}} V_{t+1}^{w}\left(\hat{W}_{t}\right)
\end{aligned}
$$

where $h_{i t}=h\left(W_{i t} ; W_{t}, H_{t}\right)=\left(\frac{W_{i t}}{W_{t}}\right)^{-\epsilon_{w}} H_{t}$.

The FOC w.r.t $\hat{W}_{t}$

$$
\begin{array}{r}
\left(1-\tau_{t}\right)\left(1-\epsilon_{w}\right)\left(\frac{\hat{W}_{t}}{W_{t}}\right)^{-\epsilon_{w}} \frac{H_{t}}{P_{t}}+\epsilon_{w} g^{\prime}\left(h\left(\hat{W}_{t} ; W_{t}, H_{t}\right)\right)\left(\frac{\hat{W}_{t}}{W_{t}}\right)^{-\epsilon_{w}-1} \frac{H_{t}}{W_{t}} \\
-\theta_{w}\left(\frac{\hat{W}_{t}}{\hat{W}_{t-1}}-\overline{\Pi^{w}}\right) \frac{H_{t}}{\hat{W}_{t-1}}+\frac{1}{1+r_{t}} V_{t+1}^{\prime}\left(\hat{W}_{t}\right)=0
\end{array}
$$

and the envelope condition

$$
V_{t+1}^{\prime}=\theta_{w}\left(\frac{\hat{W}_{t+1}}{\hat{W}_{t}}-\overline{\Pi^{w}}\right) \frac{\hat{W}_{t+1}}{\hat{W}_{t}} \frac{H_{t+1}}{\hat{W}_{t}}
$$

where we have used that $\int s=1$.

Combining the FOC and and the envelope condition

$$
\begin{array}{r}
\left(1-\tau_{t}\right)\left(1-\epsilon_{w}\right)\left(\frac{\hat{W}_{t}}{W_{t}}\right)^{-\epsilon_{w}} \frac{H_{t}}{P_{t}}+\epsilon_{w} g^{\prime}\left(h\left(\hat{W}_{t} ; W_{t}, H_{t}\right)\right)\left(\frac{\hat{W}_{t}}{W_{t}}\right)^{-\epsilon_{w}-1} \frac{H_{t}}{W_{t}} \\
-\theta_{w}\left(\frac{\hat{W}_{t}}{\hat{W}_{t-1}}-\overline{\Pi^{w}}\right) \frac{H_{t}}{\hat{W}_{t-1}}+\frac{1}{1+r_{t}} \theta_{w}\left(\frac{\hat{W}_{t+1}}{\hat{W}_{t}}-\overline{\Pi w}\right) \frac{\hat{W}_{t+1}}{\hat{W}_{t}} \frac{H_{t+1}}{\hat{W}_{t}}=0
\end{array}
$$


Using that $\hat{W}_{t}=W_{t}, \pi_{t}^{w}=\frac{W_{t}}{W_{t-1}}=\frac{\hat{W}_{t}}{\hat{W}_{t-1}}$ and $h_{i t}=H_{t}$ :

$$
\begin{aligned}
& \left(1-\tau_{t}\right)\left(1-\epsilon_{w}\right) \frac{W_{t}}{P_{t}}+\epsilon_{w} g^{\prime}\left(h\left(\hat{W}_{t} ; W_{t}, H_{t}\right)\right) \\
& -\theta_{w}\left(\pi_{t}^{w}-\overline{\Pi^{w}}\right) \pi_{t}^{w}+\frac{1}{1+r_{t}} \theta_{w}\left(\pi_{t+1}^{w}-\overline{\Pi^{w}}\right) \pi_{t+1}^{w} \frac{H_{t+1}}{H_{t}}=0
\end{aligned}
$$

